\title{
Investigation of mixed-metal (oxy)fluorides as a new class of water oxidation electrocatalysts
}

Kévin Lemoine, ${ }^{1}$ Jérôme Lhoste, ${ }^{1}$ Annie Ribaud, ${ }^{1}$ Nina Heidary, ${ }^{2}$ Vincent Maisonneuve, ${ }^{1}$ Amandine Guiet,,$^{*}$ Nikolay Kornienko ${ }^{2 *}$

${ }^{1}$ Institut des Molécules et Matériaux du Mans, UMR 6283 CNRS, Le Mans Université, Avenue Olivier Messiaen, 72085 Le Mans Cedex 9, France

${ }^{2}$ Department of Chemistry, Université de Montréal, Roger-Gaudry Building, Montreal, Quebec, H3C 3J7, Canada

* corresponding authors - amandine.guiet@univ-lemans.fr and nikolay.kornienko@umontreal.ca

Keywords: Fluorides and oxyfluorides, electrocatalysis, oxygen evolution reaction, renewable energy, heterogeneous catalysis

\begin{abstract}
:
The development of electrocatalysts for the oxygen evolution reaction (OER) is one of the principal challenges in the area of renewable energy research. Within this context, mixed-metal oxides have recently emerged as the highest performing OER catalysts. Their structural and compositional modification to further boost their activity is crucial to the wide-spread use of electrolysis technologies. In this work, we investigated a series of mixed-metal F-containing materials as OER catalysts to probe possible benefits of the high electronegativity of fluoride ions. We found that crystalline hydrated fluorides, $\mathrm{CoFe}_{2} \mathrm{~F}_{8}\left(\mathrm{H}_{2} \mathrm{O}\right)_{2}, \mathrm{NiFe}_{2} \mathrm{~F}_{8}\left(\mathrm{H}_{2} \mathrm{O}\right)_{2}$, and amorphous oxyfluorides, $\mathrm{NiFe}_{2} \mathrm{~F}_{4.4} \mathrm{O}_{1.8}$ and $\mathrm{CoFe}_{2} \mathrm{~F}_{6.6} \mathrm{O}_{0.7}$, feature excellent activity and stability for the OER in alkaline electrolyte. Subsequent electroanalytical and spectroscopic characterization hinted that the electronic structure modulation conferred by the fluoride ions aided their reactivity. Finally, the best catalyst of the set, $\mathrm{NiFe}_{2} \mathrm{~F}_{4.4} \mathrm{O}_{1.8}$, was applied as anode in an electrolyzer comprised solely of earth-abundant materials.
\end{abstract}

\section{Introduction}

The rapidly growing consumption of fossil fuels to meet the expanding energy demands of today's society is leading to negative consequences to the environment. ${ }^{1,2}$ Global warming, ocean acidification, extreme weather events and low air quality are emerging problems. To mitigate further environmental changes, fossil fuels may be replaced by alternative energy sources. Such sources include wind, hydro, and solar power, and their conversion to electrical power is being developed. However, renewable sources are typically intermittent, presenting an obstacle for their widespread use. As such, 
the conversion of renewable electricity to energy-dense fuels and value-added chemicals is important to increase the penetration of renewables in the market.

A key technology within this context is the electrolysis of $\mathrm{H}_{2} \mathrm{O}$ and/or $\mathrm{CO}_{2}$ into $\mathrm{H}_{2}$ and Ccontaining fuels. These reduction reactions are balanced by the oxidation of $\mathrm{H}_{2} \mathrm{O}$ into $\mathrm{O}_{2}$ and, as such, the continual development of highly active, cost efficient and stable oxygen evolution reaction (OER) catalysts is important to render this technology economically viable. The majority of efforts in recent years have focused on metal-oxide OER catalysts as alternatives to Ir and $\mathrm{Ru}$ oxides that were traditionally used. ${ }^{3}$ The highest performing class of these OER catalysts are iron based oxides/oxyhydroxides containing $\mathrm{Ni}$ or $\mathrm{Co}$, and in select cases, these $3 \mathrm{~d}$ metal oxides outperform the precious metal standards. ${ }^{4,5}$ The presence of strain, ${ }^{6}$ defects, ${ }^{7,8}$ and dopants ${ }^{9}$ as well as exfoliation ${ }^{10}$ and an amorphous structure ${ }^{11}$ have been shown to further boost the performance of metal oxides.

The utilization of inductive effects in electrocatalysis is an effective method to modulate materials' performance. ${ }^{12-14}$ Substitution with metals having different electronegativity will induce the tendency to donate or withdraw electron density. In the context of OER, a large number of coordinately unsaturated sites on the catalyst with an electron-deficient configuration would boost water oxidation performance. ${ }^{15-17}$ Thus, metal fluorides should be promising candidates for high-performance catalysts, given that fluorine is the highest electronegative element and therefore abstract electrons from the neighboring metals. As a consequence, the electronic structure of the transition-metal active sites is modified. However, the poor electronic conductivity of pure metal fluorides $\mathrm{M}_{\mathrm{x}} \mathrm{F}_{\mathrm{y}}$ hinders their use as highly efficient electrocatalyst. In this context, the use of oxyfluorides $\mathrm{M}_{\mathrm{x}} \mathrm{O}_{\mathrm{y}} \mathrm{F}_{\mathrm{z}}$ can be a good alternative as they offer a good chemical and thermal stability as well as an enhanced electronic conductivity while preserving key characteristics due to the strong electronegativity of fluorine ( 3.98 for $\mathrm{F}$ vs 3.44 for O). ${ }^{18}$ Indeed, oxyfluorides are present in a large range of applications such as ceramic glasses, laser cooling systems, optical amplifiers, and lithium-ion batteries. ${ }^{19,20}$ Even if the advantages of the introduction of fluorine element in changing the chemical properties and electronic structures have been demonstrated, ${ }^{21}$ only rare reports were found in the literature on fluorides or oxyfluorides as efficient catalyst for water oxidation. ${ }^{22-27}$ The lack of studies could be explained by the challenging task to prepare oxyfluorides due to the difficulty to stabilize both fluorine and oxygen anions despite their similar ionic radii (F 1.31 $\AA$, O $1.38 \AA$ ). Indeed, the number of iron-based oxyfluoride synthetic methods remains modest in the literature compared to pure oxides and fluorides..$^{21}$ As fluoride precursors are frequently sensitive to air humidity and can be easily hydrolyzed, especially at high temperatures, iron oxyfluoride FeOF was first synthesized by solid state reaction in a sealed platinum tube at $950^{\circ} \mathrm{C}$ for $24 \mathrm{~h}$ from a mixture of $\mathrm{Fe}_{2} \mathrm{O}_{3}$ and $\mathrm{FeF}_{3}{ }^{28} \mathrm{FeOF}$ was also tempted to be prepared by solid-gas reaction with the $\mathrm{F}_{2}$ through the fluorination of $\mathrm{Fe}_{3} \mathrm{O}_{4}$ magnetite at $120^{\circ} \mathrm{C}$ but only the formation of an oxyfluoride layer was observed at the surface of nanoparticles. ${ }^{29}$ In order to avoid the use of pure and sensitive fluoride precursors and toxic $F_{2}$, the synthesis of iron-based oxyfluorides using hydrated fluoride precursors was developed by 
Zhu et al. ${ }^{30}$ The authors succeed to obtain $\mathrm{FeOF}$ nanorods using $\mathrm{FeF}_{3} \cdot 3 \mathrm{H}_{2} \mathrm{O}$ in 1-propanol at $200^{\circ} \mathrm{C}$ for $24 \mathrm{~h}$. Other hydrated fluorides precursors such as $\mathrm{FeSiF}_{6} \cdot 6 \mathrm{H}_{2} \mathrm{O}$ could also be used to obtain $\mathrm{FeO}_{\mathrm{x}} \mathrm{F}_{2-\mathrm{x}}$ oxyfluorides through their thermal decomposition between 150 to $300^{\circ} \mathrm{C} .{ }^{31}$ More recently, successive dehydration at $240^{\circ} \mathrm{C}$ followed by dehydroxylation at $350^{\circ} \mathrm{C}$ of the hydrated iron hydroxyfluoride $\mathrm{FeF}_{2.2}(\mathrm{OH})_{0.8} \cdot 0.33 \mathrm{H}_{2} \mathrm{O}^{32}$ lead to the successful preparation of a lacunar oxyfluoride with the formulation $\mathrm{FeF}_{2.2} \mathrm{O}_{0.4 \square 0.4 .}{ }^{33}$

Following this strategy, the preparation of new iron-based hydrated fluorides $\mathrm{M}^{2+} \mathrm{Fe}^{3+}{ }_{2} \mathrm{~F}_{8}\left(\mathrm{H}_{2} \mathrm{O}\right)_{2}$ $(\mathrm{M}=\mathrm{Mn}, \mathrm{Co}, \mathrm{Ni}, \mathrm{Cu})$ by microwave heating assisted solvothermal synthesis from metal salts, aqueous hydrofluoric acid and methanol as solvent was previously reported. ${ }^{34}$ These hydrated crystallized phases were further calcinated under ambient air to obtain the corresponding amorphous oxyfluorides. Though those resulting amorphous oxyfluorides were tested as cathode active material in $\mathrm{Li}$-ion batteries, neither a thoroughly study of the morphology and electronic structure of those new amorphous iron-based mixed-metal oxyfluorides nor their viability as OER catalysts have been conducted.

In this paper, we set out to synthesize a series of Ni-Fe and Co-Fe (oxy)fluorides in both their crystalline and amorphous structure. Crystalline hydrated fluorides, $\mathrm{NiFe}_{2} \mathrm{~F}_{8}\left(\mathrm{H}_{2} \mathrm{O}\right)_{2}$ and $\mathrm{CoFe}_{2} \mathrm{~F}_{8}\left(\mathrm{H}_{2} \mathrm{O}\right)_{2}$ and amorphous oxyfluorides $\mathrm{NiFe}_{2} \mathrm{~F}_{4.4} \mathrm{O}_{1.8}$ and $\mathrm{CoFe}_{2} \mathrm{~F}_{6.6} \mathrm{O}_{0.7}$ materials were synthesized and characterized by XRD diffraction, thermal analysis and electronic microscopies. Their subsequent electrochemical characterization revealed each of these materials to be exceptionally active OER catalysts while Raman and X-ray photoelectron spectroscopies offered mechanistic clues to their superior activity. Finally, the highest performing $\mathrm{NiFe}_{2} \mathrm{~F}_{4.4} \mathrm{O}_{1.8}$ was combined with another earth abundant catalyst, cobalt sulfide, in a proof-of-concept overall water electrolysis system based on earthabundant materials.

\section{Results and discussion}

\subsection{Synthesis and characterization}

The hydrated fluorides, $\mathrm{NiFe}_{2} \mathrm{~F}_{8}\left(\mathrm{H}_{2} \mathrm{O}\right)_{2}$ and $\mathrm{CoFe}_{2} \mathrm{~F}_{8}\left(\mathrm{H}_{2} \mathrm{O}\right)_{2}$, were synthesized through a facile microwave heating assisted solvothermal synthesis. In brief, metal chlorides are mixed together with aqueous hydrofluoric acid $\left(\mathrm{HF}_{40 \%}\right)$ and methanol. The mixture is heated by microwave irradiation at $160^{\circ} \mathrm{C}$ for 30 min and leads to green and pink crystalline powders for $\mathrm{NiFe}_{2} \mathrm{~F}_{8}\left(\mathrm{H}_{2} \mathrm{O}\right)_{2}$ and $\mathrm{CoFe}_{2} \mathrm{~F}_{8}\left(\mathrm{H}_{2} \mathrm{O}\right)_{2}$ respectively. The X-ray powder diffraction patterns, indexed in the monoclinic system with the $C 2 / m$ space group, show that these metal hydrates are isostructural with $\mathrm{Fe}_{3} \mathrm{~F}_{8}\left(\mathrm{H}_{2} \mathrm{O}\right)_{2}$ (Figure $1 \mathbf{a}, \mathbf{b}$ and Figure S1). ${ }^{35-36}$ The structures were determined using the Rietveld method (SI). 
a)

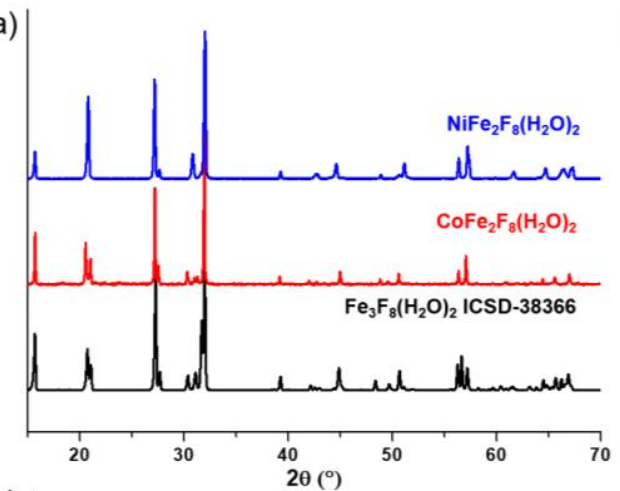

c)

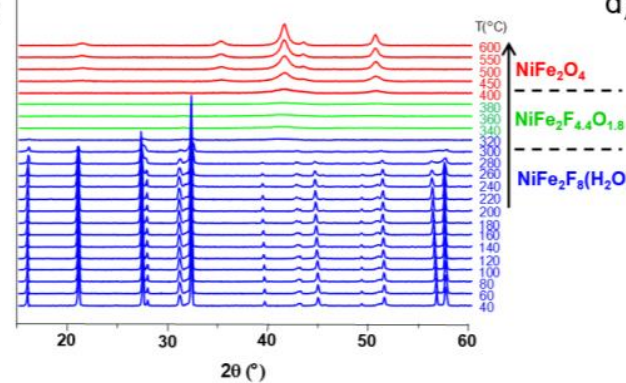

b)

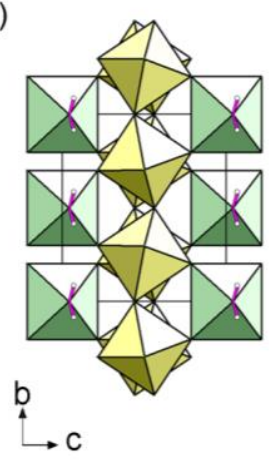

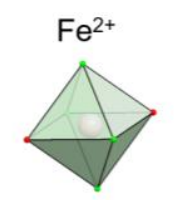

$\left[\mathrm{FeF}_{6}\left(\mathrm{H}_{2} \mathrm{O}\right)_{2}\right]^{4-}$

$\mathrm{Fe}^{3+}$

)

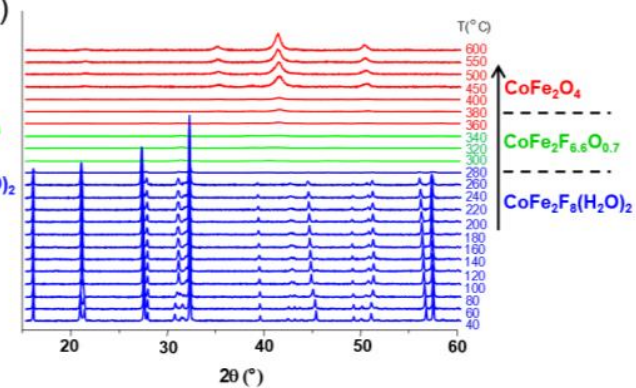

Figure 1: a) XRD patterns of $\mathrm{NiFe}_{2} \mathrm{~F}_{8}\left(\mathrm{H}_{2} \mathrm{O}\right)_{2}$ and $\mathrm{CoFe}_{2} \mathrm{~F}_{8}\left(\mathrm{H}_{2} \mathrm{O}\right)_{2}$ hydrated phases collected at room temperature compared to that of $\mathrm{Fe}_{3} \mathrm{~F}_{8}\left(\mathrm{H}_{2} \mathrm{O}\right)_{2}$ (ICSD-38366), b) Projection along $a$ axis of $\mathrm{MFe}_{2} \mathrm{~F}_{8}\left(\mathrm{H}_{2} \mathrm{O}\right)_{2}$ structure. Thermal evolution of the X-ray diffractograms under dry air of c) $\mathrm{NiFe}_{2} \mathrm{~F}_{8}\left(\mathrm{H}_{2} \mathrm{O}\right)_{2}$ and d) $\mathrm{CoFe}_{2} \mathrm{~F}_{8}\left(\mathrm{H}_{2} \mathrm{O}\right)_{2}$.

Those resulting crystalline hydrated fluorides were used as precursors to obtain the corresponding amorphous oxyfluorides by an appropriate treatment under ambient air. Their structural and compositional evolutions with the temperature were monitored by thermodiffraction and thermogravimetric analyses (Figure 1 c,d and Figure S2). The diffraction peaks positions of the hydrated crystallized phases (blue domain) shift above $180^{\circ} \mathrm{C}$ to lower $2 \theta$ values and their intensity decreases. The last phenomenon is related to the elimination of water and hydrogen fluoride molecules leading to the amorphous phase (green domain) as confirmed by Mass Spectroscopy coupled thermogravimetric (MS-TGA) analysis under $\mathrm{N}_{2}$ (Figure 2). Further calcination and hydrolysis at higher temperature allows the formation of the corresponding crystallized spinel $\mathrm{M}^{2+} \mathrm{Fe}^{3+}{ }_{2} \mathrm{O}_{4}$ structures. The formulations of the intermediate stabilized amorphous oxyfluorides were determined through the following reaction equations. For $\mathrm{NiFe}_{2} \mathrm{~F}_{8}\left(\mathrm{H}_{2} \mathrm{O}\right)_{2}$, the experimental weight loss $(21.0 \mathrm{wt} \%)$ corresponds to $\mathrm{NiFe}_{2} \mathrm{~F}_{4.4} \mathrm{O}_{1.8}$ following the reaction (1):

$$
\mathrm{NiFe}_{2} \mathrm{~F}_{8}\left(\mathrm{H}_{2} \mathrm{O}\right)_{2} \rightarrow \mathrm{NiFe}_{2} \mathrm{~F}_{4.4} \mathrm{O}_{1.8}+3.6 \mathrm{HF}+0.2 \mathrm{H}_{2} \mathrm{O}
$$

And in the case of $\mathrm{CoFe}_{2} \mathrm{~F}_{8}\left(\mathrm{H}_{2} \mathrm{O}\right)_{2}$, to the reaction (2). It must be noted that $\mathrm{CoFeF}_{5} 7 \mathrm{H}_{2} \mathrm{O}$ as impurity was detected by XRD (Figure S1) and quantified (8\% molar) by Mossbauer Spectrometry. ${ }^{34}$ This amount has to be taken into account to obtain the $16.2 \%$ experimental weight loss. 

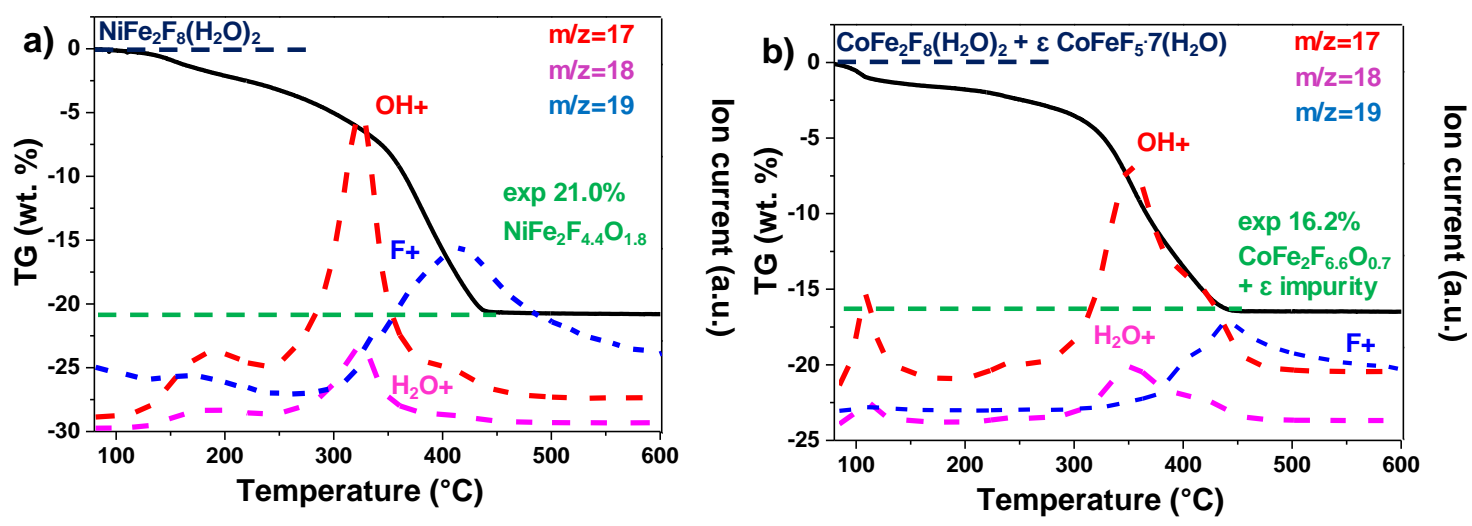

Figure 2: MS coupled TGA analysis under $\mathrm{N}_{2}$ of a) $\mathrm{NiFe}_{2} \mathrm{~F}_{8}\left(\mathrm{H}_{2} \mathrm{O}\right)_{2}$ and b) $\mathrm{CoFe}_{2} \mathrm{~F}_{8}\left(\mathrm{H}_{2} \mathrm{O}\right)_{2}$.

Compared to TGA under $\mathrm{N}_{2}$, TGA under ambient air shows identical first weight losses (Figure S2) but for temperatures above $400^{\circ} \mathrm{C}$, slow weight losses related to a hydrolysis occur that leads to spinel oxides (Table S1) according to reaction (3):

$$
\mathrm{M}^{2+} \mathrm{Fe}_{2} \mathrm{~F}_{8-2 \mathrm{x}} \mathrm{O}_{\mathrm{x}}+(4-\mathrm{x}) \mathrm{H}_{2} \mathrm{O} \rightarrow \mathrm{M}^{2+} \mathrm{Fe}_{2} \mathrm{O}_{4}+(8-2 \mathrm{x}) \mathrm{HF}
$$

Consequently, the stabilized amorphous oxyfluorides phases were prepared by thermal decomposition of $\mathrm{M}^{2+} \mathrm{Fe}^{3+}{ }_{2} \mathrm{~F}_{8}\left(\mathrm{H}_{2} \mathrm{O}\right)_{2}$ under air for $1 \mathrm{~h}$ at $340^{\circ} \mathrm{C}$ and $320^{\circ} \mathrm{C}$ for $\mathrm{Ni}$ and $\mathrm{Co}$, respectively. Electronic microscopies (SEM and TEM) together with nitrogen sorption have been performed to determine the size and the morphology of the Ni-Fe and Co-Fe based compounds before and after calcination. As revealed by SEM (Figure S3), microsized particles are obtained for the hydrate fluorides which is in good accordance with the sharpness of the peaks in the diffractograms (Figure 1 a). The decomposition of those crystalline fluorides leads in both cases to a significant decrease of the particle size (Figure S3). In order to probe the atomic distribution in those resulting amorphous oxyfluorides, energy dispersive spectroscopy (EDS) elemental mapping, carried out by SEM, shows that both metals $(\mathrm{Ni} / \mathrm{Fe}$ and $\mathrm{Co} / \mathrm{Fe})$ were homogenously dispersed without phase segregation within the resolution capacity of the instrument (Figure S3). The final Fe to metal ratio of 2 present in the initial hydrated fluoride precursors was also confirmed. This nanostructuration though the thermal treatment was further investigated by transmission electron microscopy (TEM) and $\mathrm{N}_{2}$ sorption. As shown in Figure 3 for high magnification, fine structures are observed for both materials and in the case of $\mathrm{Ni}-\mathrm{Fe}$ amorphous oxyfluorides, pores of less than $10 \mathrm{~nm}$ could be detected. This emerging porosity is probably related to the precursor's decomposition. Indeed, the $\mathrm{HF}$ and $\mathrm{H}_{2} \mathrm{O}$ gas molecules liberated during the thermal decomposition could act as a self-generated porogen. ${ }^{37}$ The porosity enhancement between $\mathrm{NiFe}_{2} \mathrm{~F}_{4.4} \mathrm{O}_{1.8}$ and $\mathrm{CoFe}_{2} \mathrm{~F}_{6.6} \mathrm{O}_{0.7}$ seems to be related to the increase of the number of lost HF molecules. Indeed, as shown in reaction (1) and (2), a release of $3.6 \mathrm{HF}$ molecules is determined for $\mathrm{NiFe}_{2} \mathrm{~F}_{8}\left(\mathrm{H}_{2} \mathrm{O}\right)_{2}$ whereas only 1.4 for $\mathrm{CoFe}_{2} \mathrm{~F}_{8}\left(\mathrm{H}_{2} \mathrm{O}\right)_{2}$. The amorphous character of those oxyfluorides, evidenced by thermodiffraction, was further confirmed by TEM as diffuse electron diffraction patterns were obtained 
by selected area electron diffraction (SEAD) on several grains and no distinct diffraction fringes at higher resolution could be observed (Figure 3). TEM analyses could not be performed on the hydrated fluorides as they were not stable under the electron beam.

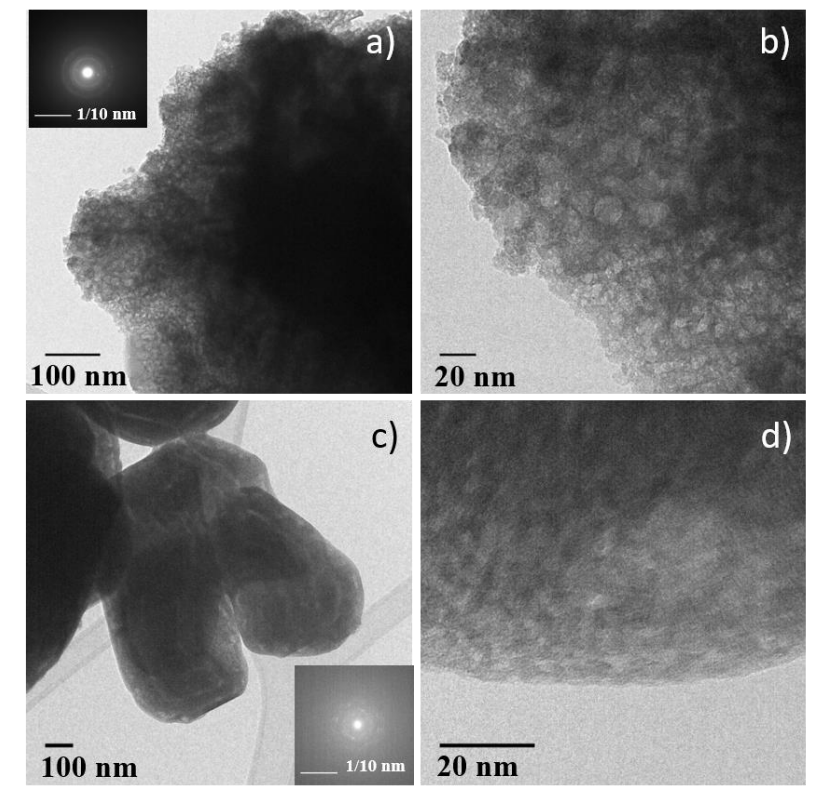

Figure 3: TEM micrographs of a), b) $\mathrm{NiFe}_{2} \mathrm{~F}_{4.4} \mathrm{O}_{1.8}$ and c), d) $\mathrm{CoFe}_{2} \mathrm{~F}_{6.6} \mathrm{O}_{0.7}$. Inserts: corresponding SAED.

$\mathrm{N}_{2}$ sorption measurements were carried out to determine the specific surface area ( $\mathrm{SABET}$ ) of the fluorinated materials before and after thermal treatment. As expected for microsized hydrated fluorides, the measured surface areas are less than $10 \mathrm{~m}^{2} \cdot \mathrm{g}^{-1}$. However, for the corresponding oxyfluorides obtained after calcination, the $\mathrm{SA}_{\mathrm{BET}}$ is drastically increased up to $76 \mathrm{~m}^{2} \cdot \mathrm{g}^{-1}$ and $30 \mathrm{~m}^{2} \cdot \mathrm{g}^{-1}$ for $\mathrm{NiFe}_{2} \mathrm{~F}_{4.4} \mathrm{O}_{1.8}$ and $\mathrm{CoFe}_{2} \mathrm{~F}_{6.6} \mathrm{O}_{0.7}$ respectively confirming the porogen effect of the $\mathrm{H}_{2} \mathrm{O}$ and $\mathrm{HF}$ release during the thermal treatment. $\mathrm{N}_{2}$ adsorption/desorption isotherms shows type IV hysteresis corresponding to mesoporous structure according to the IUPAC classification. ${ }^{38}$ In the case of $\mathrm{NiFe}_{2} \mathrm{~F}_{4.4} \mathrm{O}_{1.8}$, the $\mathrm{BJH}$ pore-size distribution analysis (Figure 4 a Inset) shows an average pore diameter inferior to $10 \mathrm{~nm}$ for $\mathrm{Ni}-\mathrm{Fe}$ phase, value in good agreement with the TEM observation. 

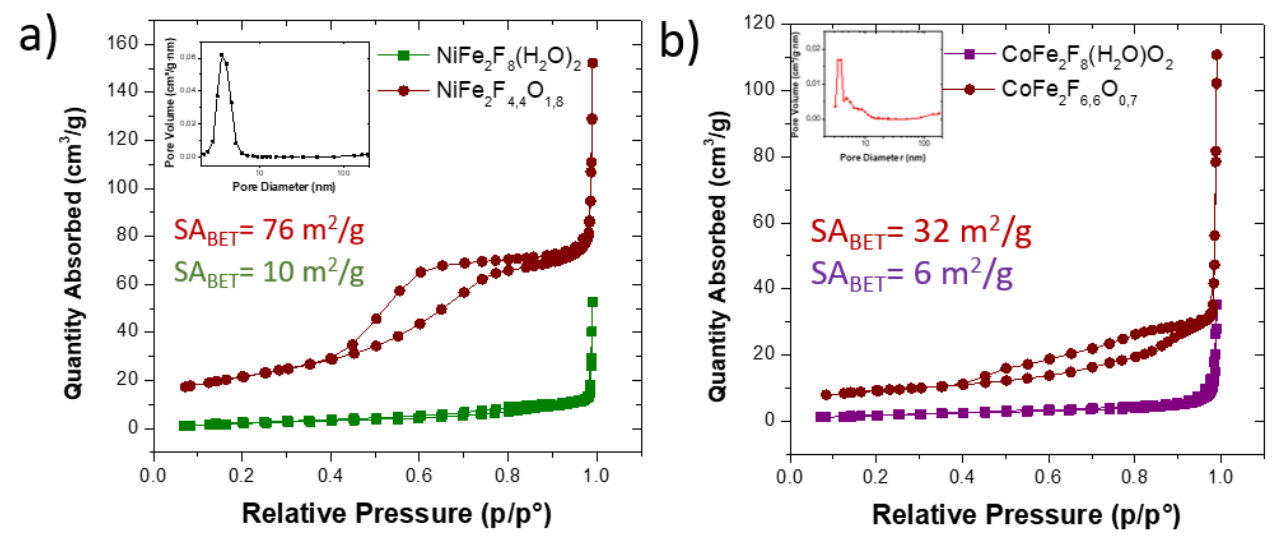

Figure 4: $\mathrm{N}_{2}$ adsorption/desorption isotherm of $\mathrm{NiFe}_{2} \mathrm{~F}_{4.4} \mathrm{O}_{1.8}$ a) and $\mathrm{CoFe}_{2} \mathrm{~F}_{6.6} \mathrm{O}_{0.7} \mathrm{~b}$ ) before (green/purple) and after calcination (brown). Inset: Corresponding BJH pore size distribution analyzed from the desorption branch.

X-ray photoelectron spectroscopy (XPS) was subsequently utilized to probe the electronic structure of the transition metal species within the hydrated fluoride and oxyfluoride catalysts (together labelled (oxy)fluorides). In these measurements, both the binding peak position and peak shape provide element-specific information on oxidation state and chemical environment. The binding energies, and specifically the $2 \mathrm{p}_{3 / 2}$ peaks (denoted with a $*$ in Figure 5), of our materials were compared to those found in the national institute of science and technology (NIST) database. ${ }^{39}$ The Ni2 $\mathrm{p}_{3 / 2}$ binding energies were determined to be at 858.1 and $855.6 \mathrm{eV}$ for $\mathrm{NiFe}_{2} \mathrm{~F}_{8}\left(\mathrm{H}_{2} \mathrm{O}\right)_{2}$ and $\mathrm{NiFe}_{2} \mathrm{~F}_{4.4} \mathrm{O}_{1.8}$, respectively (Figure 5 a). The values for $\mathrm{NiF}_{2}$ have been measured at 857.4-858.2 eV. In comparison, the $\mathrm{Ni}_{2} \mathrm{p}_{3 / 2}$ peak is typically found at $855-856 \mathrm{eV}$ for $\mathrm{Ni}(\mathrm{OH})_{2}$, and at $854-855 \mathrm{eV}$ for $\mathrm{NiO}$. This indicates that the $\mathrm{F}$ withdraws electron density from the $\mathrm{Ni}$ in our materials as their binding energies, especially that of $\mathrm{NiFe}_{2} \mathrm{~F}_{8}\left(\mathrm{H}_{2} \mathrm{O}\right)_{2}$, are positively shifted in comparison to $\mathrm{Ni}(\mathrm{II})$ oxides/hydroxides. The Co2 $\mathrm{p}_{3 / 2}$ peaks of $\mathrm{CoFe}_{2} \mathrm{~F}_{8}\left(\mathrm{H}_{2} \mathrm{O}\right)_{2}$ and $\mathrm{CoFe}_{2} \mathrm{~F}_{6.6} \mathrm{O}_{0.7}$ were centered at $782.9 \mathrm{eV}$ and 781.2 , respectively (Figure 5 b). Likewise, these peaks are shifted slightly higher in binding energy as compared to $\mathrm{CoO}$ ( $780.4 \mathrm{ev})$, $\mathrm{Co}(\mathrm{OH})_{2}(781-782 \mathrm{eV}), \mathrm{Co}(\mathrm{OH}) \mathrm{O}(\sim 780 \mathrm{eV})$ and $\mathrm{Co}_{3} \mathrm{O}_{4}(779-780 \mathrm{eV})$ and closer to those of $\mathrm{CoF}_{2}(783.0$ $\mathrm{eV})$ and $\mathrm{CoF}_{3}(782.4 \mathrm{eV})$. The same can be said for the $\mathrm{Fe} 2 \mathrm{p}_{3 / 2}$ peaks, which were found at $712.9 \mathrm{eV}$ $\left(\mathrm{NiFe}_{2} \mathrm{~F}_{4.4} \mathrm{O}_{1.8}\right.$ and $\left.\mathrm{CoFe}_{2} \mathrm{~F}_{6.6} \mathrm{O}_{0.7}\right)$ and $714.4 \mathrm{eV}\left(\mathrm{NiFe}_{2} \mathrm{~F}_{8}\left(\mathrm{H}_{2} \mathrm{O}\right)_{2}\right.$ and $\left.\mathrm{CoFe}_{2} \mathrm{~F}_{8}\left(\mathrm{H}_{2} \mathrm{O}\right)_{2}\right)$ (Figure 5 c). These shifted the most in comparison to (709-710 eV), $\mathrm{FeOOH}(711-712 \mathrm{eV}), \mathrm{Fe}_{3} \mathrm{O}_{4}(709-710 \mathrm{eV})$ and $\mathrm{Fe}_{2} \mathrm{O}_{3}$ (710-711 eV) and are closer to $\mathrm{FeF}_{3}(\sim 714 \mathrm{eV})$. The $\mathrm{O} 1 \mathrm{~s}$ spectra for $\mathrm{NiFe}_{2} \mathrm{~F}_{8}\left(\mathrm{H}_{2} \mathrm{O}\right)_{2}$ and $\mathrm{CoFe}_{2} \mathrm{~F}_{8}\left(\mathrm{H}_{2} \mathrm{O}\right)_{2}$ are similar to that of pure water $(\sim 533 \mathrm{eV})$ while the oxyfluoride $\mathrm{O} 1 \mathrm{~s}$ spectra featured only a red-shifted peak at $\sim 530 \mathrm{eV}$ as the $\mathrm{O}$ was incorporated in the lattice (Figure S4). Similarly, the F1s spectra displayed a peak at $685.2 \mathrm{eV}$ for $\mathrm{NiFe}_{2} \mathrm{~F}_{8}\left(\mathrm{H}_{2} \mathrm{O}\right)_{2}$ and $\mathrm{CoFe}_{2} \mathrm{~F}_{8}\left(\mathrm{H}_{2} \mathrm{O}\right)_{2}$ that is slightly red-shifted to $684.8 \mathrm{eV}$ upon their conversion to oxyfluorides.

In summation, the XPS investigation points to all of the transition metals in the new synthesized (oxy)fluorides being electron-poor relative to their oxide analogues, induces by the presence of the 
highly electronegative $\mathrm{F}$ anions. The Fe metal cation likely experiences the largest magnitude of these effects and this is especially pronounced in the hydrated fluorides. Because the exact position of the peaks is not linearly proportional to oxidation state and electronic structure, we do not yet draw quantitative conclusions regarding the magnitude of inductive effects conferred by the $\mathrm{F}$ anion.

a)

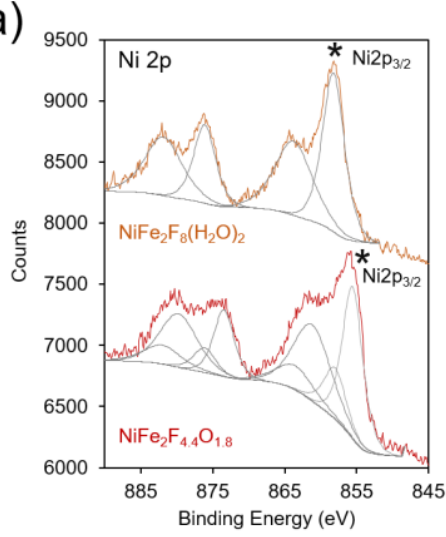

b)

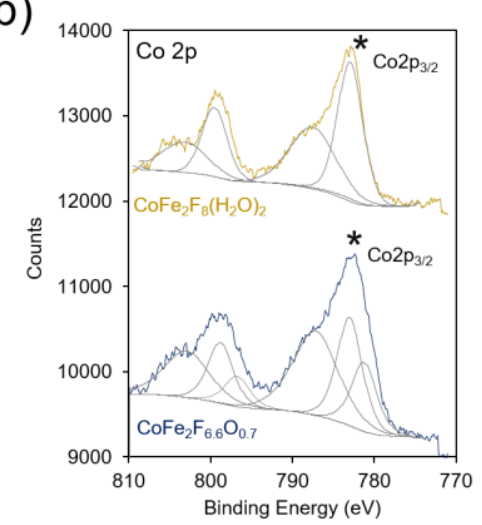

c)

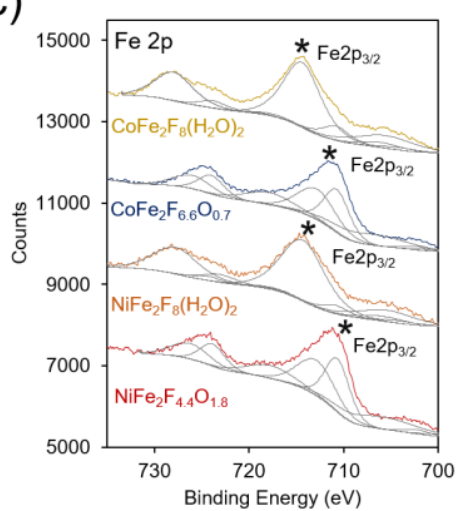

Figure 5: XPS spectra of the (oxy)fluorides and oxyfluorides. The Ni2p3/2 a), Co2 $\mathrm{p}_{3 / 2}$ b) and $\mathrm{Fe} 2 \mathrm{p}_{3 / 2} \mathrm{c}$ ) were acquired and spectra subsequently fit to (grey traces) compare with database data of $F$-free oxides. The $2 p_{3 / 2}$ peaks discussed are denoted with a*.

\subsection{Electrocatalysis}

To evaluate the electrochemical performance of the (oxy) fluoride materials, the as-prepared powders were sonicated together with a nafion binder and carbon nanotube conductive adhesive to generate a catalyst ink. The catalyst ink was then drop-cast onto a carbon paper electrode and dried prior testing in $1 \mathrm{M} \mathrm{KOH}$. Several ( 3-6) electrodes were prepared for each measurement and error bars represent standard deviation from multiple electrodes. Cyclic Voltammetry (CV) tests of the catalysts in $1 \mathrm{M} \mathrm{KOH}$ electrolyte illustrated that each material undergoes a series of redox-changes prior to OER catalysis, indicating the transformation to a catalytically active state (Figure $\mathbf{6}$ a). This is common in mixed-metal oxides of $\mathrm{Ni}, \mathrm{Co}$, and $\mathrm{Fe}$, in which typically the surface evolves into an oxyhydroxide phase at a potential in the range of where our redox peaks are located. ${ }^{4}$ This may indicate that the surface of our (oxy)fluorides also evolve into similar phases. The differences in peak shapes here reflect variance in the physical and electronic structure of the transition metals in each material. We also did not witness changes in the CV shape or increases in OER activity as is sometime observed in Ni-Fe and Co-Fe oxides as a result of structural or compositional changes during this conditioning phase ${ }^{40,41}$ Following this redox transformation, the OER kinetics are exceptionally high, evidenced by the low Tafel slopes (40-60 $\mathrm{mV} \mathrm{dec}^{-1}$ range) (Figure $6 \mathbf{~ b}$ ) and low overpotential to attain a geometric current density of 10 $\mathrm{mA} \mathrm{cm}^{-2}(250-350 \mathrm{mV}$ ) (Figure $6 \mathbf{c}$ ). The performance of the (oxy)fluorides is comparable to state-of- 
the-art mixed-metal oxide OER cataysts. ${ }^{42,43}$ In this series, the $\mathrm{NiFe}_{2} \mathrm{~F}_{4.4} \mathrm{O}_{1.8}$ was consistently the highest performing material. The series of materials' performance is likely also influenced by their surface area and consequently the quantity of active sites exposed to the solution, with $\mathrm{NiFe}_{2} \mathrm{~F}_{4.4} \mathrm{O}_{1.8}$ exhibiting both the highest surface area $\left(76 \mathrm{~m}^{2} \cdot \mathrm{g}^{-1}\right)$ and electrocatalytic activity.

The precise benefit to OER catalysis conferred by the $\mathrm{F}$ species within $\mathrm{NiFe}_{2} \mathrm{~F}_{4.4} \mathrm{O}_{1.8}$ is illustrated by comparing its electrochemical response to the crystalline $\mathrm{NiFe}_{2} \mathrm{O}_{4}$ (Figure S5). The electronwithdrawing nature of $\mathrm{F}$ is evident through a shift in the redox potential for the Ni-oxidation peak, which is shifted $50 \mathrm{mV}$ more positive. This indicates that the $\mathrm{Ni}$ is harder to oxidize in $\mathrm{NiFe}_{2} \mathrm{~F}_{4.4} \mathrm{O}_{1.8}$. However, once oxidized the $\mathrm{NiFe}_{2} \mathrm{~F}_{4.4} \mathrm{O}_{1.8}$ catalyst oxidized water much more rapidly, with an earlier onset potential and quickly increasing OER current. In contrast, $\mathrm{NiFe}_{2} \mathrm{O}_{4}$ requires $<100 \mathrm{mV}$ more overpotential to attain similar currents.

Electrochemical Impedance Spectroscopy (EIS) was performed at $300 \mathrm{mV}$ overpotential for all samples and the data, which was in the form of a semi-circle, was fit using a Randles equivalent circuit model (Figure 6 d,e). However, $\mathrm{NiFe}_{2} \mathrm{~F}_{8}\left(\mathrm{H}_{2} \mathrm{O}\right)_{2}$ featured two semi-circles, indicative of both a chargetransfer resistance and a significant resistance from the material's limited conductivity had to be fit with a separate model. The models and fitting are presented in Figure S6. In these spectra, the high-frequency intercept at $\sim 7$ ohms reflects the solution-resistance and the low-frequency intercept of the semicircle at around $20-40 \mathrm{ohm}$ resistance corresponds to the charge transfer kinetics at the catalyst surface. The lowest charge-transfer resistance of $\mathrm{NiFe}_{2} \mathrm{~F}_{4.4} \mathrm{O}_{1.8}(23 \pm 3 \mathrm{ohm})$ corresponds to its rapid OER catalysis. Finally, the stability of (oxy)fluorides was evaluated through chronopotentiometric measurements at 10 mA.cm ${ }^{-2}$ (Figure $\left.6 \mathbf{f}\right)$. Over a period of $20 \mathrm{~h}$, each sample experiences only minimal $(\sim 30 \mathrm{mV})$ performance losses. The stability of $\mathrm{NiFe}_{2} \mathrm{~F}_{4.4} \mathrm{O}_{1.8}$ is demonstrated with a duration of $\sim 270 \mathrm{~h}$ (Figure 6 f Inset). Prior to efforts at optimization of material structure and morphology, these initial electrochemical results already indicate that these (oxy)fluorides are excellent candidates for OERenabled technologies such as electrolyzer or air batteries. 
a)

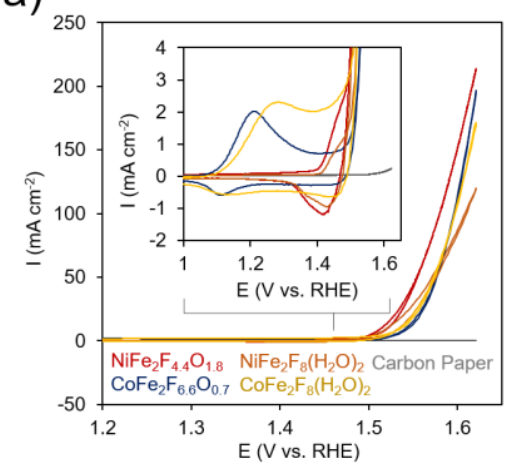

d)

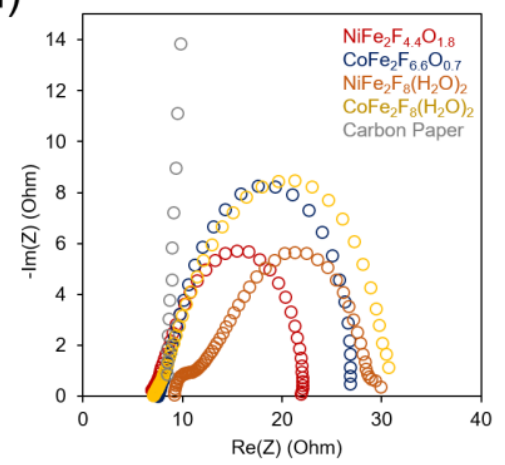

b)

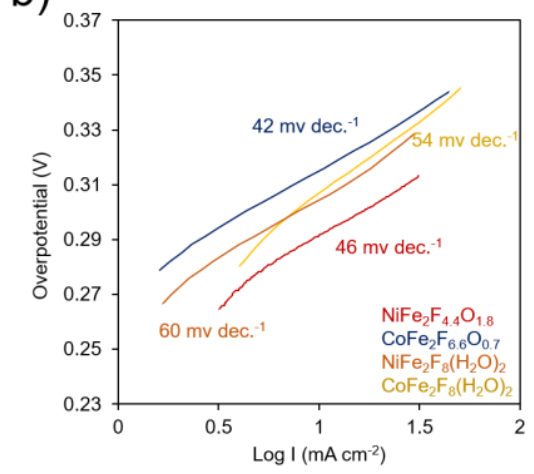

c)

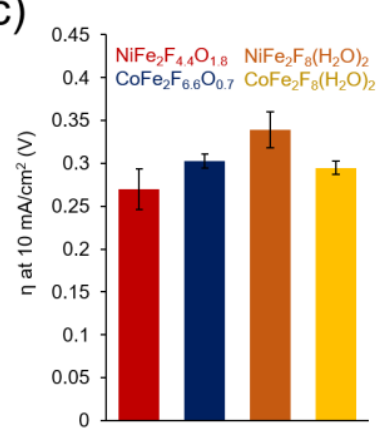

e)

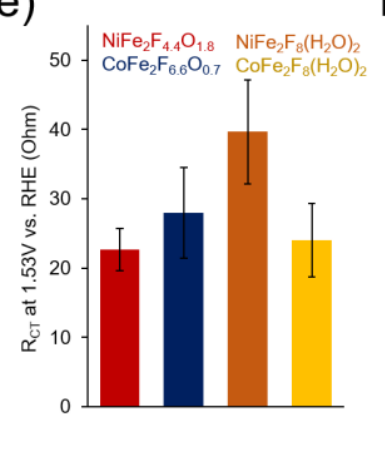

f)

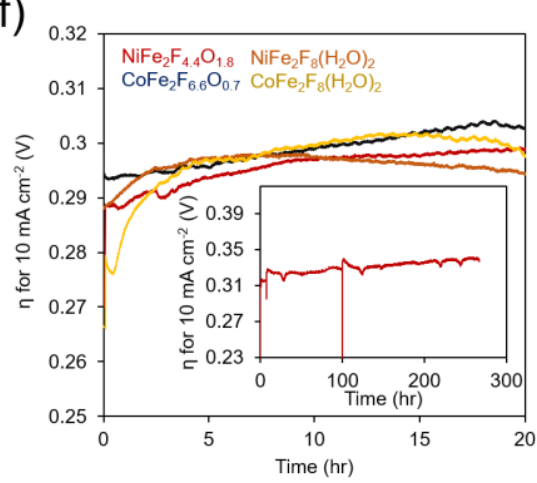

Figure 6: Electrochemical characterization of oxyfluoride catalysts. Cyclic voltammetry of each material's currents and

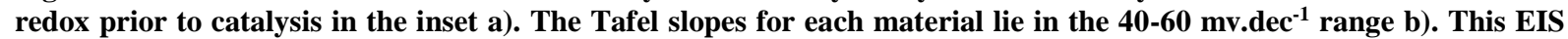
measurements, acquired at $300 \mathrm{mV}$ overpotential, point to $\mathrm{NiFe}_{2} \mathrm{~F}_{4.4} \mathrm{O}_{1.8}$ as the catalyst with the lowest charge transfer resistance d), e). The performance was tested over a prolonged $20 \mathrm{~h}$ chronopotentiometric test at $10 \mathrm{~mA} . \mathrm{cm}^{-2} \mathrm{f}$ ), with $\mathrm{NiFe}_{2} \mathrm{~F}_{4.4} \mathrm{O}_{1.8}$ measured over $270 \mathrm{~h}$.

To elucidate the molecular dynamics (oxy)fluorides throughout the catalytic process, Raman spectroscopy was used to probe them before and after catalysis $(4 \mathrm{~h}$ chronoamperometry at $300 \mathrm{mV}$ overpotential in $1 \mathrm{M} \mathrm{KOH})$. Spectra of crystalline $\mathrm{NiFe}_{2} \mathrm{~F}_{8}\left(\mathrm{H}_{2} \mathrm{O}\right)_{2}$ and $\mathrm{CoFe}_{2} \mathrm{~F}_{8}\left(\mathrm{H}_{2} \mathrm{O}\right)_{2}$ shows several strong bands, as common to crystalline metal-oxides (Figure 7 a,b). However, the bands of hydrated fluorides significantly widen and decrease in intensity, indicating a loss of crystallinity during catalysis. In contrast, the spectra of the amorphous oxyfluorides, $\mathrm{NiFe}_{2} \mathrm{~F}_{4.4} \mathrm{O}_{1.8}$ and $\mathrm{CoFe}_{2} \mathrm{~F}_{6.6} \mathrm{O}_{0.7}$, show a small evolution with weak and wide bands before and after OER testing. Likely, the OER-active state of each material is an amorphous final state on the material's surface and is at a higher-valence oxidation state than the as-made material. The spectra of these materials after catalysis do not match those of $\mathrm{NiOOH},{ }^{44}$ $\mathrm{CoOOH},{ }^{44}$ amorphous $\mathrm{CoO}_{\mathrm{x}},{ }^{45},{ }^{46}$ or various iron oxide phases, ${ }^{47}$ indicating that the surface of the (oxy)fluorides tested here are not transformed to $\mathrm{NiOOH}$ or $\mathrm{CoOOH}$.

The TEM analysis was also conducted on the amorphous $\mathrm{NiFe}_{2} \mathrm{~F}_{4.4} \mathrm{O}_{1.8}$ and $\mathrm{CoFe}_{2} \mathrm{~F}_{6.6} \mathrm{O}_{0.7}$ after the OER catalysis (Figure S7). In both cases, these oxyfluorides remain amorphous confirming the Raman analysis. Their morphology slightly changes to thin sheet-like appearance and no additional amorphous layer is observed. Metal leaching was also observed during catalysis. Indeed, the $\mathrm{Fe}^{+3}$ to $\mathrm{M}^{2+}$ 
ratios measured by EDS-TEM vary from 2 to 1.4 for $\mathrm{NiFe}_{2} \mathrm{~F}_{4.4} \mathrm{O}_{1.8}$ corresponding to a Fe leaching and from 2.1 to 2.4 for $\mathrm{CoFe}_{2} \mathrm{~F}_{6.6} \mathrm{O}_{0.7}$ corresponding to a Co leaching. Those differences in the composition through leaching are in good agreement with the slight differences in the Raman spectra.

In order to probe surface intermediates and rate-limiting steps of the OER cycle of the (oxy)fluoride materials, we utilized methanol oxidation as facile method to detect surface-bound $* \mathrm{OH}$. As $* \mathrm{OH}$ is a very electrophilic intermediate, it will react with methanol, and thus give rise to methanol oxidation currents when present in substantial quantities. ${ }^{48}$ Upon the addition of $10 \mathrm{mM}$ methanol, we noted enhanced currents beginning at $1.0 \mathrm{~V}$ vs. RHE for all examples except for $\mathrm{NiFe}_{2} \mathrm{~F}_{8}\left(\mathrm{H}_{2} \mathrm{O}\right)_{2}($ Figure S8). This result points to (though does not prove) $* \mathrm{OH}$ coverage on the (oxy)fluoride surfaces prior to OER initiation and that the * $\mathrm{OH}$ deprotonation step as possibly being rate limiting. On the other hand, the limiting step for $\mathrm{NiFe}_{2} \mathrm{~F}_{8}\left(\mathrm{H}_{2} \mathrm{O}\right)_{2}$ may be the adsorption of $* \mathrm{OH}$. This is especially interesting as even changes in a material's stoichiometry induce notable changes in mechanism.

While a complete mechanistic picture of these oxyfluoride materials is not yet available, there exist a number of promising approaches to obtain complementary pieces to this puzzle. X-ray absorption spectroscopy (XAS), especially when operated in-situ, has been previously used to elucidate how changes in oxidation states and chemical environments of the transition metal species influence catalytic activity in metal-oxide materials and would be similarly useful to this system. ${ }^{43}, 49-52$ XPS, performed in specialized instrumental setups would also provide complementary information regarding electronic structure as a function of applied bias and reaction time. ${ }^{53}$ Furthermore, techniques such as electrochemical quartz crystal microbalance measurements may impart information on voltagedependent surface or bulk reconstruction by cross-comparing currents and in-situ changes in mass. ${ }^{54}$ 
a)

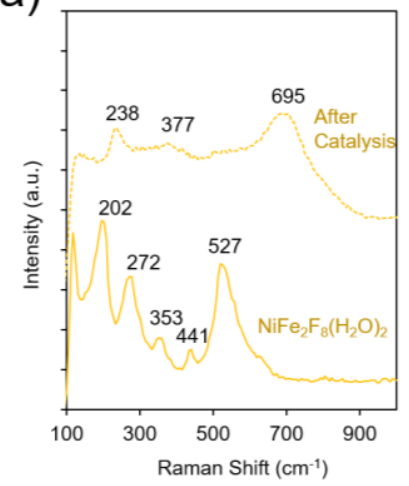

c)

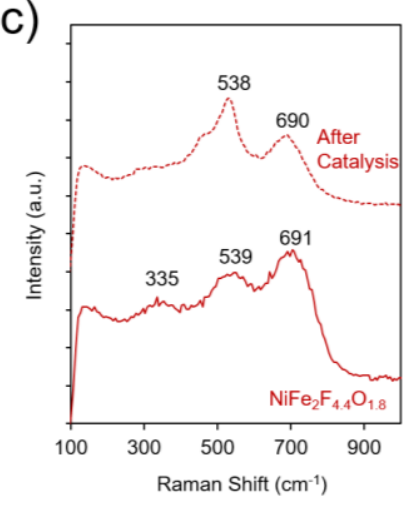

b)

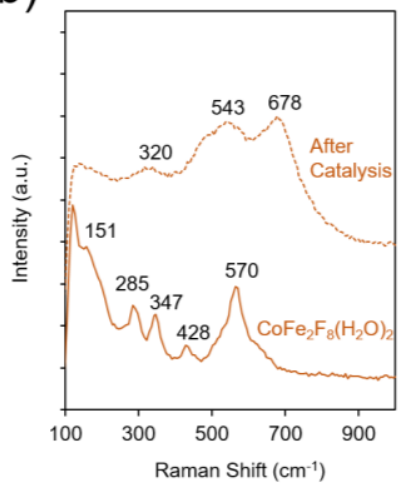

d)

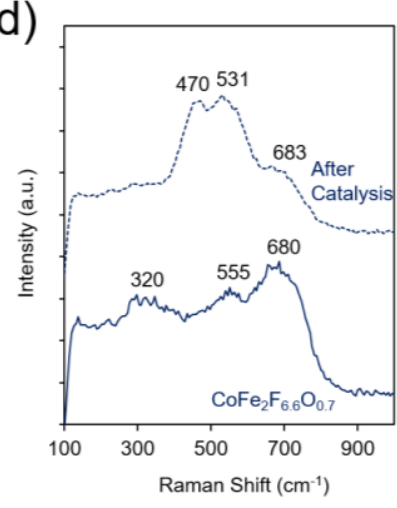

Figure 7: Raman spectroscopy of the (oxy)fluorides before and after catalytic testing ( $4 \mathrm{~h}$ at $1.53 \mathrm{~V}$ in $1 \mathrm{M} \mathrm{KOH}$ ). The spectra of crystalline $\mathrm{NiFe}_{2} \mathrm{~F}_{8}\left(\mathrm{H}_{2} \mathrm{O}\right)_{2}$ a) and $\mathrm{CoFe}_{2} \mathrm{~F}_{8}\left(\mathrm{H}_{2} \mathrm{O}\right)_{2}$ b) exhibit a number of strong bands which are lost and give way to broader bands after catalysis. In contrast, the amorphous $\mathrm{NiFe}_{2} \mathrm{~F}_{4.4} \mathrm{O}_{1.8} \mathrm{c}$ ) and $\mathrm{CoFe}_{2} \mathrm{~F}_{6.6} \mathrm{O}_{0.7} \mathrm{~d}$ ) feature broader bands which undergo considerably less changes during catalytic testing.

As a proof of concept, the best performing material, $\mathrm{NiFe}_{2} \mathrm{~F}_{4.4} \mathrm{O}_{1.8}$, was combined with another earth-abundant hydrogen evolution reaction (HER) catalyst, cobalt sulfide (CoSx), ${ }^{55,56}$ and utilized in an overall water electrolysis cell (Figure 8 a and Figure S9). In a two-electrodes configuration, overall water electrolysis initiated at $\sim 1.60 \mathrm{~V}$ and reached $100 \mathrm{~mA} \mathrm{~cm}^{-2}$ at $1.80 \mathrm{~V}$. Chronopotentiometric testing

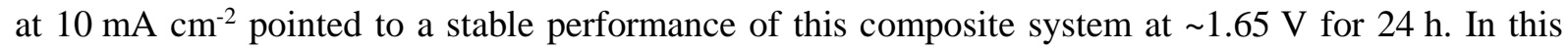
configuration, the OER overpotential was $\sim 270 \mathrm{mV}$, in line with some of the highest-performing Ni-Fe oxides $^{42}$ and the HER overpotential was $\sim 100 \mathrm{mV}$. This metric is comparable to the performance achieved with benchmark precious-metal (e.g. Pt, Ir, Ru) containing systems ${ }^{57}$ that also need typically $1.55-1.6 \mathrm{~V}$ to reach $10 \mathrm{~mA} \mathrm{~cm}{ }^{-2}$ and points to the promise of oxyfluorides as cost-effective OER components of next-generation electrochemical technologies. 

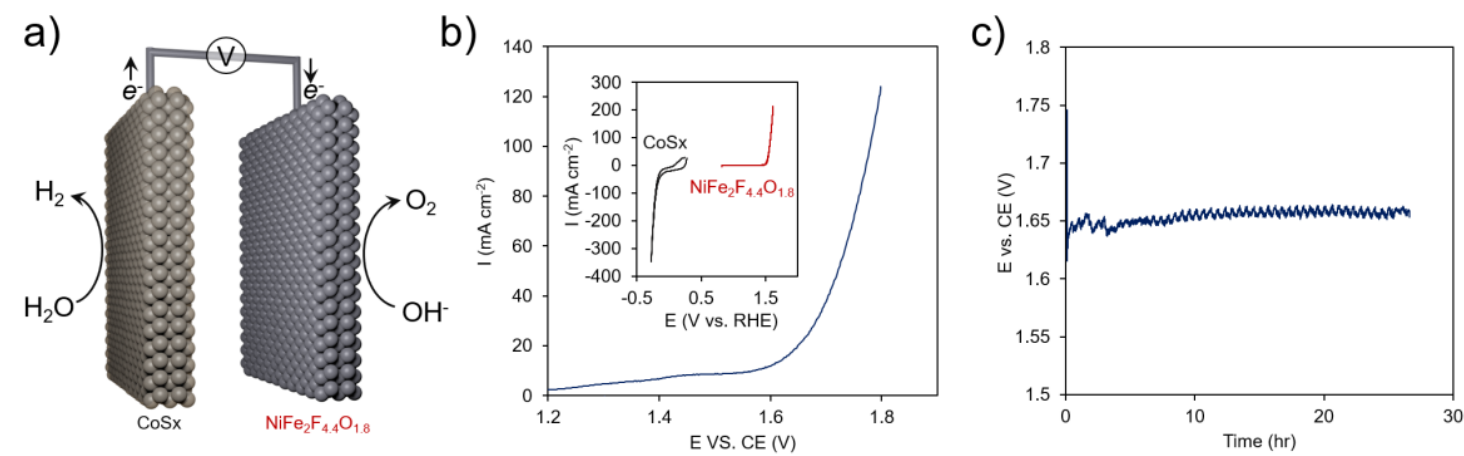

Figure 8: Overall water electrolysis with $\mathrm{NiFe}_{2} \mathrm{~F}_{4.4} \mathrm{O}_{1.8}$ as anode. A $\mathrm{NiFe}_{2} \mathrm{~F}_{4.4} \mathrm{O}_{1.8}$ was integrated with a $\mathrm{CoSx}$ cathode to put together an overall water electrolysis system comprised of earth-abundant materials a). This system featured an onset of $\sim 1.60 \mathrm{~V}$ and required $\sim 1.65$ volts to generate a stable current of $10 \mathrm{~mA} . \mathrm{cm}^{-2} \mathrm{~b}$ ).

\section{Concluding Remarks}

In summary, we present a study on the synthesis and electrocatalytic applications of mixedmetal (oxy)fluorides as OER catalysts. Crystalline hydrated fluorides, $\mathrm{CoFe}_{2} \mathrm{~F}_{8}\left(\mathrm{H}_{2} \mathrm{O}\right)_{2}$ and $\mathrm{NiFe}_{2} \mathrm{~F}_{8}\left(\mathrm{H}_{2} \mathrm{O}\right)_{2}$, were prepared by microwave heating assisted solvothermal synthesis. Subsequent calcination of the hydrated fluorides leads to the formation of amorphous oxyfluorides $\mathrm{NiFe}_{2} \mathrm{~F}_{4.4} \mathrm{O}_{1.8}$ and $\mathrm{CoFe}_{2} \mathrm{~F}_{6.6} \mathrm{O}_{0.7}$. The (oxy)fluorides are speculated to benefit from the fluorine anions withdrawing electron density away from the $\mathrm{Co}, \mathrm{Ni}$, and $\mathrm{Fe}$ species, which are likely responsible for the exceptional electrocatalytic properties of each material. Finally, the best catalyst, $\mathrm{NiFe}_{2} \mathrm{~F}_{4.4} \mathrm{O}_{1.8}$, associated with a CoSx HER catalyst leads to a highly performing water electrolyzer comprise of only earth-abundant element catalysts. This study may open up avenues towards the utility of (oxy)fluoride materials for energy-related applications and rational routes for harnessing inductive effects conferred by fluorine species.

\section{Materials and methods}

\section{Synthesis}

The hydrated fluorides $\mathrm{M}^{2+} \mathrm{Fe}^{3+}{ }_{2} \mathrm{~F}_{8}\left(\mathrm{H}_{2} \mathrm{O}\right)_{2}\left(\mathrm{M}^{2+}=\mathrm{Co}\right.$, Ni) was obtained by solvothermal reaction using a MARS-5 microwave Digestion System (CEM Corp.) from starting reactants of chloride precursors (Alfa Aesar), $9.45 \mathrm{~mL}$ of absolute methanol 'MeOH' (233 mmol, 24.7 mol.L-1, 99.8\%, Sigma Aldrich) and $0.55 \mathrm{ml}$ hydrofluoric acid solution (15 mmol, $27.6 \mathrm{~mol} . \mathrm{L}^{-1}$, Riedel De Haen). A constant concentration $\left[\mathrm{M}^{\mathrm{II}}\right]+\left[\mathrm{Fe}^{\mathrm{III}}\right]=0.1 \mathrm{~mol} \cdot \mathrm{L}^{-1}$, a ratio $\left[\mathrm{Fe}^{\mathrm{III}}\right] /\left[\mathrm{M}^{\mathrm{II}}\right]=2$ and a constant volume of liquid (HF and $\left.\mathrm{MeOH}\right)$ were fixed. The $\mathrm{M}^{\mathrm{II}} / \mathrm{Fe}^{\mathrm{II}} / \mathrm{HF} / \mathrm{MeOH}$ ratio is $1 / 2 / 44 / 699$. The mixtures are placed in Teflon autoclaves and heated at $160^{\circ} \mathrm{C}$ for 30 min with stirring. After cooling, the solid products are filtered, washed with $2 \mathrm{~mL}$ of ethanol and dried in a furnace under air.

$\mathrm{CoFe}_{2} \mathrm{~F}_{8}\left(\mathrm{H}_{2} \mathrm{O}\right)_{2}$ and $\mathrm{NiFe}_{2} \mathrm{~F}_{8}\left(\mathrm{H}_{2} \mathrm{O}\right)_{2}$ were put in a furnace at $320^{\circ} \mathrm{C}$ and $340^{\circ} \mathrm{C}$, respectively, during $1 \mathrm{~h}$ (heating/cooling rate of $2^{\circ} \mathrm{C} / \mathrm{min}$ ) giving the amorphous oxyfluorides with $\mathrm{M}^{2+} \mathrm{M}^{3+}{ }_{2} \mathrm{~F}_{8-2 \mathrm{x}} \mathrm{O}_{\mathrm{x}}$ formulations. 


\section{Characterization methods}

X-Ray powder diffraction (XRPD): X-ray diffraction patterns were collected in the range $10^{\circ} \leq 2 \theta \leq$ $150^{\circ}$ on a Panalytical MPD-PRO diffractometer equipped with a linear X'celerator detector with a $\mathrm{CoK}_{\alpha}$ radiation (1.789 $\AA$ ) used to avoid the X-ray fluorescence. Rietveld refinements were performed by using the Fullprof profile refinement program. This diffractometer belongs to the "X-ray Diffusion and Diffraction" technical platform of IMMM (Le Mans University). Data were collected in the [10-100 $\left.{ }^{\circ}\right]$ $2 \theta$ scattering angle range with a $0.0131^{\circ}$ step.

Scanning Electronic Microscopy (SEM): SEM images of the powders were obtained using a JEOL microscope (JSM 6510LV) at an acceleration voltage of $20 \mathrm{kV}$. Elementary quantitative microanalyses were performed using an Energy Dispersive Spectrometry (EDS) OXFORD detector (AZtec software). The microscope belongs to the "Electron Microscopy" technical platform of IMMM (Le Mans University).

Transmission electron microscopy (TEM): The TEM study (SAED and HREM) was performed on a JEOL JEM $2100 \mathrm{HR}$ electron microscope operating at $200 \mathrm{kV}$ and equipped with a side entry $\pm 35^{\circ}$ double-tilt specimen holder. The microscope belongs to the "Electron Microcopy" technical platform of IMMM (Le Mans University). The sample for transmission electron microscopy investigation were prepared by ultrasonically dispersing the raw powder in ethanol, depositing a drop of the resulting suspension onto a holey carbon-coated copper grid and finally drying the grid in air.

Nitrogen sorption: $\mathrm{N}_{2}$ sorption isotherms were measured at $77 \mathrm{~K}$ using a TriStar II 3020 (Micrometrics). The film samples were degassed under vacuum at $100^{\circ} \mathrm{C}$ for $12 \mathrm{~h}$ prior measurement. The surface areas were calculated using the Brunauer-Emmett-Teller (BET) method.

Thermal analysis: Mass Spectroscopy coupled Thermo Gravimetric Analysis- (TGA-MS) was performed using a Netzch STA 449 F3 coupled with a QMS 403 C mass spectrometer. The thermoanalytical curves were recorded together with the ion current curves in the multiple ions detection probe. A constant purge nitrogen gas flow of $80 \mathrm{~mL} \cdot \mathrm{min}^{-1}$ and a constant heating rate of $5^{\circ} \mathrm{C}$.min-1 were applied. The thermogravimetric (TGA) experiments were carried out with a thermoanalyzer SETARAM TGA 92 with a heating rate of $5^{\circ} \mathrm{C} \cdot \mathrm{min}^{-1}$ from room temperature up to $900^{\circ} \mathrm{C}$ under dry air (Alphagaz, mixture of oxygen (20\%) with nitrogen $\left.(80 \%), \mathrm{H}_{2} \mathrm{O}<3 \mathrm{ppm}\right)$. X-ray thermodiffraction (HT-XRD) was performed under dry air in an Anton Parr XRK 900 high temperature furnace with the diffractometer already described. The samples were heated from 40 to $600^{\circ} \mathrm{C}$ at a heating rate of $10^{\circ} \mathrm{C} \cdot \mathrm{min}^{-1}$. X-ray diffraction patterns were recorded in the $5-60^{\circ} 2$ theta range with a scan time of $10 \mathrm{~min}$ at $20^{\circ} \mathrm{C}$ intervals from room temperature to 400 and at $100^{\circ} \mathrm{C}$ intervals from 400 to $600^{\circ} \mathrm{C}$.

Electrochemical measurements: To fabricate electrodes, sample powders were sonicated in ethanol together with $1 \%$ nafion and $1 \%$ multi-walled carbon nanotubes $(40 \mathrm{~nm}$ diameter, purchased from Sigma Aldrich) to make a catalyst ink. The ink was pipetted onto Toray carbon paper to load $1 \mathrm{mg} \mathrm{cm}^{-2}$ of 
catalyst and dried at $80^{\circ} \mathrm{C}$ for 20 minutes. Electrochemical characterization was performed using a Biologic VMP 150 potentiostat equipped with impedance capability. Prior to voltammetry or amperometry, ohmic drop compensation (85\%) was performed with EC-Lab software. A carbon rod and $\mathrm{Ag} / \mathrm{AgCl}$ electrode were used as counter and reference electrodes. To ensure that the potential of the reference electrode did not drift over time, the reference was periodically checked against a "master" electrode which did not undergo testing. Methanol oxidation was performed by measuring two consecutive $\mathrm{CVs}$, one in $1.0 \mathrm{~mol} . \mathrm{L}^{-1} \mathrm{KOH}$ and another immediately after the addition of a small quantity of methanol to reach $10 \mathrm{mM}$ concentration. For two-electrode measurements of overall water electrolysis, $\mathrm{CoSx}$ was prepared through electrodeposition onto carbon paper from a $\mathrm{CoCl}_{2}$ and thiourea containing aqueous solution, using a well-established recipe. ${ }^{56}$ Briefly, a carbon paper electrode was cycled in $100 \mathrm{mM} \mathrm{CoCl}_{2}$ and $0.5 \mathrm{M}$ thiourea between -1.2 and $0.3 \mathrm{~V}$ vs. $\mathrm{Ag} / \mathrm{AgCl}$ for 30 cycles, rinsed with water, dried and kept in ambient conditions prior to use.

Raman Spectroscopy: Raman spectra were acquired using a Renishaw Invia spectrometer and a 514 $\mathrm{nm} 30 \mathrm{~W}$ laser. Spectra were first acquired at low power (99.5\% laser attenuation) to ensure that the laser irradiation of the samples did not alter them. Typical acquisition times were 180 seconds. Several spectra were acquired to verify sample homogeneity and representative spectra were incorporated into the manuscript.

X-ray photoelectron spectroscopy: XPS spectra were acquired with a VG ESCALAB 3 Mark II spectrometer with a $\mathrm{Mg} \mathrm{K} \alpha$ source operating at $300 \mathrm{~W}(15 \mathrm{kV}, 20 \mathrm{~mA})$. Prior to characterization, samples were deposited onto conductive copper tape and no other modifications made. The $\mathrm{C} 1 \mathrm{~s}$ peak $(285.0 \mathrm{eV})$ was used for energy calibration and the background for all spectra was subtracted using a Shirley method. High-resolution scans were taken at $0.1 \mathrm{eV}$ steps following a survey scan at $1.0 \mathrm{eV}$ step size.

\section{Acknowledgements}

The authors give thanks to French Research Ministry for a doctoral grant. The authors attached to the IMMM institute to gratefully acknowledge the "X-ray Diffusion and Diffraction" and the "Electron Microcopy" technical platforms of IMMM (Le Mans University). The authors also give thanks to Josianne Lefebvre for help with XPS experiments. N.K. and N.H. acknowledge the NSERC Discovery Grant RGPIN-2019-05927.

\section{References}

1. M. I. Hoffert, K. Caldeira, A. K. Jain, E. F. Haites, L. D. Harvey, S. D. Potter, M. E. Schlesinger, S. H. Schneider, R. G. Watts and T. M. Wigley, Nature, 1998, 395, 881.

2. P. Nejat, F. Jomehzadeh, M. M. Taheri, M. Gohari and M. Z. A. Majid, Renewable Sustainable Energy Rev., 2015, 43, 843-862.

3. C. Hu, L. Zhang and J. Gong, Energy Environ. Sci., 2019, DOI: 10.1039/C9EE01202H. 
4. L. Trotochaud, J. K. Ranney, K. N. Williams and S. W. Boettcher, J. Am. Chem. Soc., 2012, 134, 17253-17261.

5. F. Dionigi and P. Strasser, Adv. Energy Mater., 2016, 6, 1600621.

6. D. Zhou, S. Wang, Y. Jia, X. Xiong, H. Yang, S. Liu, J. Tang, J. Zhang, D. Liu, L. Zheng, Y. Kuang, X. Sun and B. Liu, Angew. Chem. Int. Ed., 2019, 58, 736-740.

7. G. Ou, F. Wu, K. Huang, N. Hussain, D. Zu, H. Wei, B. Ge, H. Yao, L. Liu, H. Li, Y. Shi and H. Wu, ACS Appl. Mater. Interfaces, 2019, 11, 3978-3983.

8. H. Wang, H.-W. Lee, Y. Deng, Z. Lu, P.-C. Hsu, Y. Liu, D. Lin and Y. Cui, Nat. Commun., 2015, 6, 7261.

9. K. Fan, H. Chen, Y. Ji, H. Huang, P. M. Claesson, Q. Daniel, B. Philippe, H. Rensmo, F. Li, Y. Luo and L. Sun, Nat. Commun., 2016, 7, 11981.

10. L. Hui, Y. Xue, B. Huang, H. Yu, C. Zhang, D. Zhang, D. Jia, Y. Zhao, Y. Li, H. Liu and Y. Li, Nat. Commun., 2018, 9, 5309.

11. A. Indra, P. W. Menezes, N. R. Sahraie, A. Bergmann, C. Das, M. Tallarida, D. Schmeißer, P. Strasser and M. Driess, J. Am. Chem. Soc., 2014, 136, 17530-17536.

12. D. A. Kuznetsov, B. Han, Y. Yu, R. R. Rao, J. Hwang, Y. Román-Leshkov and Y. Shao-Horn, Joule, 2018, 2, 225-244.

13. N. Kornienko, Joule, 2018, 2, 207-209.

14. J. H. Zagal and M. T. M. Koper, Angew. Chem. Int. Ed., 2016, 55, 14510-14521.

15. S. Zhao, Y. Wang, J. Dong, C.-T. He, H. Yin, P. An, K. Zhao, X. Zhang, C. Gao, L. Zhang, J. Lv, J. Wang, J. Zhang, A. M. Khattak, N. A. Khan, Z. Wei, J. Zhang, S. Liu, H. Zhao and Z. Tang, Nat. Energy, 2016, 1, 16184.

16. L. Tao, C.-Y. Lin, S. Dou, S. Feng, D. Chen, D. Liu, J. Huo, Z. Xia and S. Wang, Nano Energy, 2017, 41, 417-425.

17. W. Yang, Z. Wang, W. Zhang and S. Guo, Trends Chem., 2019, 1, 259-271.

18. S. Polishchuk, L. Ignat'eva, Y. V. Marchenko and V. Bouznik, Glass Phys. Chem., 2011, 37, 1-20.

19. W. B. Im, N. George, J. Kurzman, S. Brinkley, A. Mikhailovsky, J. Hu, B. F. Chmelka, S. P. DenBaars and R. Seshadri, Adv. Mater., 2011, 23, 2300-2305.

20. N. Pereira, F. Badway, M. Wartelsky, S. Gunn and G. Amatucci, J. Electrochem. Soc., 2009, 156, A407-A416.

21. M. Leblanc, V. Maisonneuve and A. Tressaud, Chem. Rev., 2015, 115, 1191-1254.

22. K. Liang, L. Guo, K. Marcus, S. Zhang, Z. Yang, D. E. Perea, L. Zhou, Y. Du and Y. Yang, ACS Catal., 2017, 7, 8406-8412.

23. X. Fan, Y. Liu, S. Chen, J. Shi, J. Wang, A. Fan, W. Zan, S. Li, W. A. Goddard and X.-M. Zhang, Nat. Commun., 2018, 9, 1809.

24. P. Chen, T. Zhou, S. Wang, N. Zhang, Y. Tong, H. Ju, W. Chu, C. Wu and Y. Xie, Angew. Chem. Int. Ed., 2018, 57, 15471-15475.

25. Y. Xue, Y. Wang, H. Liu, X. Yu, H. Xue and L. Feng, Chem. Commun., 2018, 54, 6204-6207.

26. H. Han, J. Woo, Y.-R. Hong, Y.-C. Chung and S. Mhin, ACS Appl. Energy Mater., 2019, 2, 39994007.

27. C. Pei, H. Chen, B. Dong, X. Yu and L. Feng, J. Power Sources, 2019, 424, 131-137.

28. F. J. Brink, R. L. Withers and J. G. Thompson, J. Solid State Chem., 2000, 155, 359-365.

29. H. Zhou, J. Nanda, S. K. Martha, J. Adcock, J. C. Idrobo, L. Baggetto, G. M. Veith, S. Dai, S. Pannala and N. J. Dudney, J. Phys. Chem. Lett., 2013, 4, 3798-3805.

30. J. Zhu and D. Deng, Angew. Chem. Int. Ed., 2015, 54, 3079-3083.

31. N. Pereira, F. Badway, M. Wartelsky, S. Gunn and G. G. Amatucci, J. Electrochem. Soc., 2009, 156, A407-A416.

32. M. Duttine, D. Dambournet, N. Penin, D. Carlier, L. Bourgeois, A. Wattiaux, K. W. Chapman, P. J. Chupas, H. Groult, E. Durand and A. Demourgues, Chem. Mater., 2014, 26, 4190-4199.

33. M. Burbano, M. Duttine, B. J. Morgan, O. J. Borkiewicz, K. W. Chapman, A. Wattiaux, A. Demourgues, H. Groult, M. Salanne and D. Dambournet, J. Phys. Chem. Lett., 2019, 10, 107112. 
34. K. Lemoine, L. Zhang, J.-M. Grenèche, A. Hémon-Ribaud, M. Leblanc, a. guiet, C. Galven, J.-M. Tarascon, V. Maisonneuve and J. Lhoste, J. Phys. Chem. C., 2019, DOI: 10.1021/acs.jpcc.9b06055.

35. E. Herdtweck, Zeitschrift für Anorganische und Allgemeine Chemie, 1983, 501, 131-136.

36. M. Leblanc, G. Ferey, Y. Calage and R. De Pape, J. Solid State Chem., 1984, 53, 360-368.

37. A. Lemaire, J. C. Rooke, L.-H. Chen and B.-L. Su, Langmuir, 2011, 27, 3030-3043.

38. K. S. Sing, Pure Appl. Chem., 1985, 57, 603-619.

39. Journal, 2019, DOI: 10.18434/T4T88K.

40. L. Trotochaud, S. L. Young, J. K. Ranney and S. W. Boettcher, J. Am. Chem. Soc., 2014, 136, 6744-6753.

41. M. Gao, W. Sheng, Z. Zhuang, Q. Fang, S. Gu, J. Jiang and Y. Yan, J. Am. Chem. Soc., 2014, 136, 7077-7084.

42. M. Gong and H. Dai, Nano Res., 2015, 8, 23-39.

43. N.-T. Suen, S.-F. Hung, Q. Quan, N. Zhang, Y.-J. Xu and H. M. Chen, Chem. Soc. Rev., 2017, 46, 337-365.

44. B. S. Yeo and A. T. Bell, J. Phys. Chem. C., 2012, 116, 8394-8400.

45. B. S. Yeo and A. T. Bell, J. Am. Chem. Soc., 2011, 133, 5587-5593.

46. J. Tyczkowski, R. Kapica and J. Łojewska, Thin Solid Films, 2007, 515, 6590-6595.

47. D. L. A. de Faria, S. Venâncio Silva and M. T. de Oliveira, J. Raman Spectrosc., 1997, 28, 873878.

48. H. B. Tao, Y. Xu, X. Huang, J. Chen, L. Pei, J. Zhang, J. G. Chen and B. Liu, Joule, 2019, 3, 14981509.

49. N. Li, D. K. Bediako, R. G. Hadt, D. Hayes, T. J. Kempa, F. von Cube, D. C. Bell, L. X. Chen and D. G. Nocera, Proc. Natl. Acad. Sci. U. S. A., 2017, 114, 1486.

50. A. Bergmann, T. E. Jones, E. Martinez Moreno, D. Teschner, P. Chernev, M. Gliech, T. Reier, H. Dau and P. Strasser, Nat. Catal., 2018, 1, 711-719.

51. L. J. Enman, M. B. Stevens, M. H. Dahan, M. R. Nellist, M. C. Toroker and S. W. Boettcher, Angew. Chem. Int. Ed., 2018, 57, 12840-12844.

52. D. Friebel, M. W. Louie, M. Bajdich, K. E. Sanwald, Y. Cai, A. M. Wise, M.-J. Cheng, D. Sokaras, T.-C. Weng, R. Alonso-Mori, R. C. Davis, J. R. Bargar, J. K. Nørskov, A. Nilsson and A. T. Bell, J. Am. Chem. Soc., 2015, 137, 1305-1313.

53. H. Ali-Löytty, M. W. Louie, M. R. Singh, L. Li, H. G. Sanchez Casalongue, H. Ogasawara, E. J. Crumlin, Z. Liu, A. T. Bell, A. Nilsson and D. Friebel, J. Phys. Chem. C., 2016, 120, 2247-2253.

54. N. Kornienko, N. Heidary, G. Cibin and E. Reisner, Chem. Sci., 2018, 9, 5322-5333.

55. Y. Sun, C. Liu, D. C. Grauer, J. Yano, J. R. Long, P. Yang and C. J. Chang, J. Am. Chem. Soc., 2013, 135, 17699-17702.

56. N. Kornienko, J. Resasco, N. Becknell, C.-M. Jiang, Y.-S. Liu, K. Nie, X. Sun, J. Guo, S. R. Leone and P. Yang, J. Am. Chem. Soc., 2015, 137, 7448-7455.

57. C. C. L. McCrory, S. Jung, I. M. Ferrer, S. M. Chatman, J. C. Peters and T. F. Jaramillo, J. Am. Chem. Soc., 2015, 137, 4347-4357. 


\section{TOC Image:}

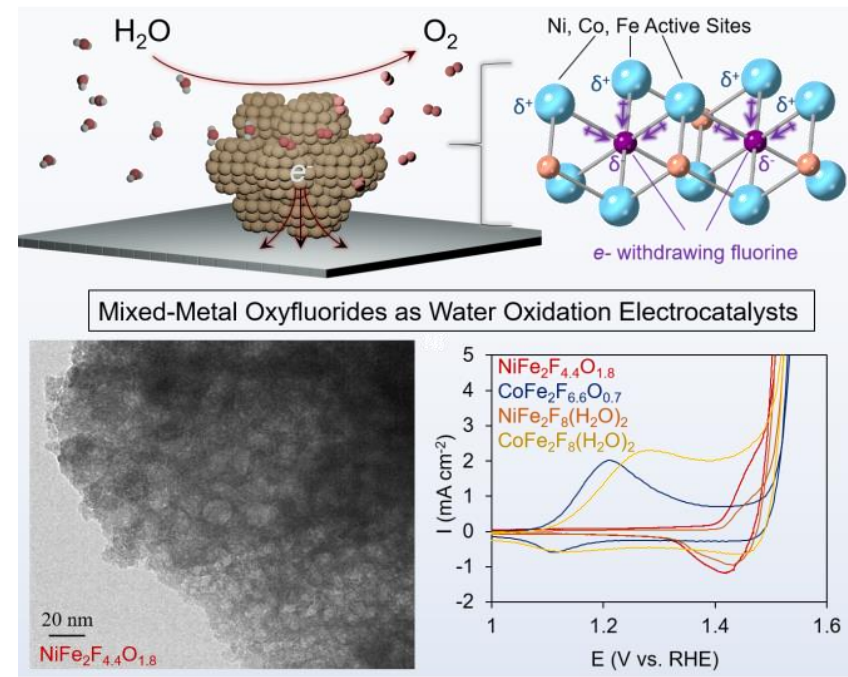


Supplementary information for:

\section{Investigation of amorphous mixed-metal (oxy)fluorides as a new class of water oxidation electrocatalysts}

Kévin Lemoine, ${ }^{1}$ Jérôme Lhoste, ${ }^{1}$ Annie Ribaud, ${ }^{1}$ Nina Heidary, ${ }^{2}$ Vincent Maisonneuve, ${ }^{1}$ Amandine Guiet, ${ }^{1 *}$ Nikolay Kornienko ${ }^{2 *}$

${ }^{1}$ Institut des Molécules et Matériaux du Mans, UMR 6283 CNRS, Le Mans Université, Avenue Olivier Messiaen, 72085 Le Mans Cedex 9, France

${ }^{2}$ Department of Chemistry, Université de Montréal, Roger-Gaudry Building, Montreal, Quebec, H3C 3J7, Canada

* corresponding authors - amandine.guiet@univ-lemans.fr and nikolay.kornienko@umontreal.ca 

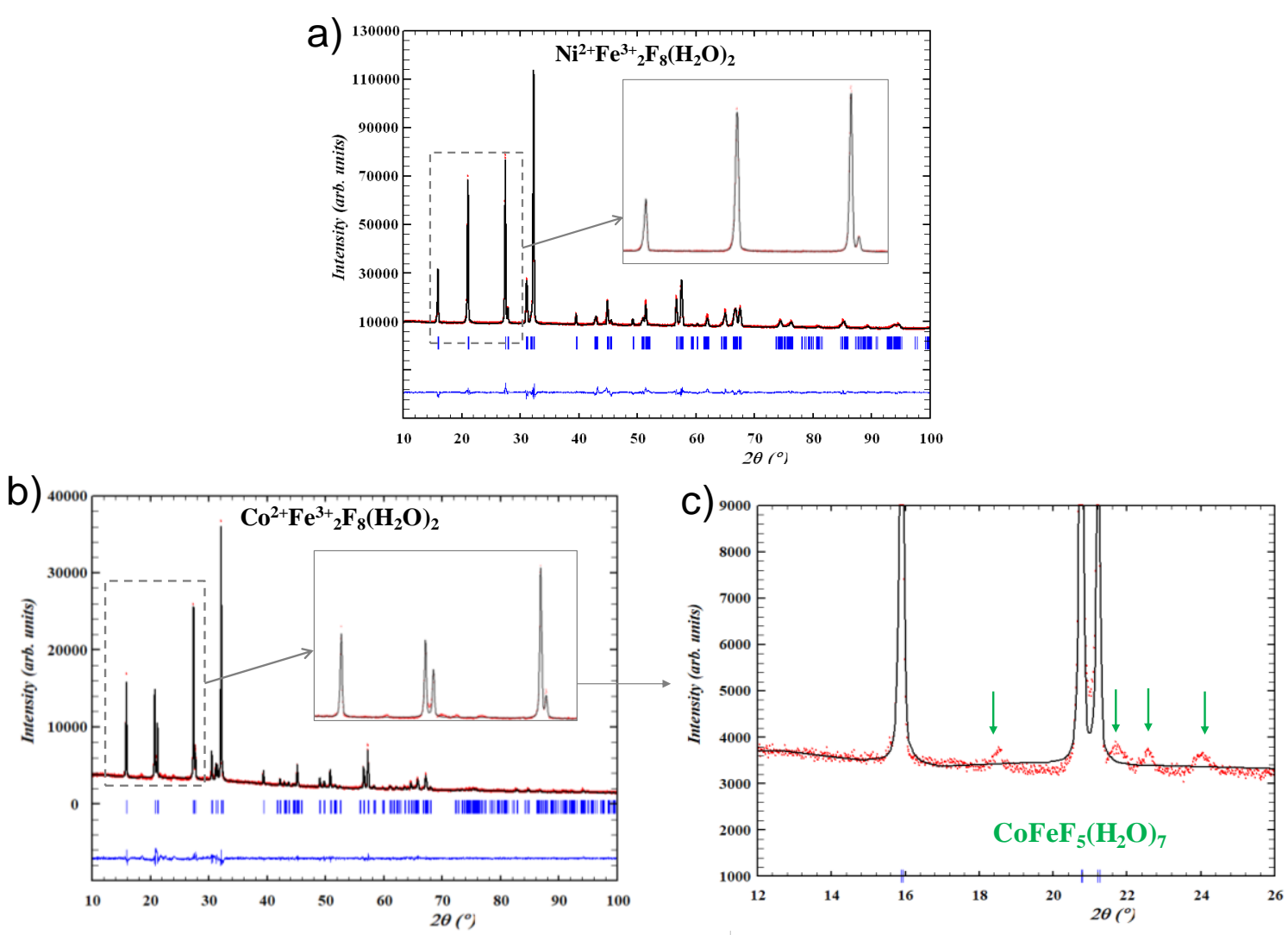

Figure S9: Rietveld refinement of the X-ray patterns of a) $\mathrm{NiFe}_{2} \mathrm{~F}_{8}\left(\mathrm{H}_{2} \mathrm{O}\right)_{2}$, b) and c) $\mathrm{CoFe}_{2} \mathrm{~F}_{8}\left(\mathrm{H}_{2} \mathrm{O}\right)_{2}$ using the structural model of $\mathrm{Fe}_{3} \mathrm{~F}_{8}\left(\mathrm{H}_{2} \mathrm{O}\right)_{2}$ (ICSD-38366). Vertical markers give Bragg peak positions of the $\mathrm{C} 2 / \mathrm{m}$ space group.
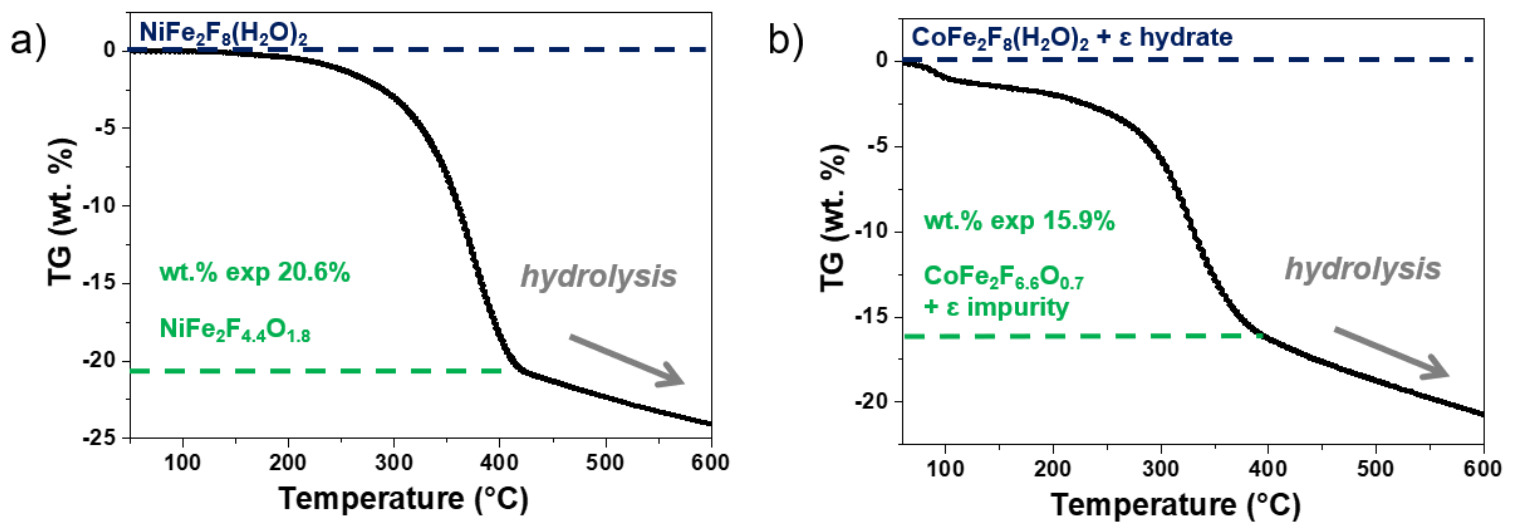

Figure S10: TGA analysis under dry air of a) $\mathrm{Ni}^{2+} \mathrm{Fe}^{3+}{ }_{2} \mathrm{~F}_{8}\left(\mathrm{H}_{2} \mathrm{O}\right)_{2}$ and b) $\mathrm{Co}^{2+} \mathrm{Fe}^{3+}{ }_{2} \mathrm{~F}_{8}\left(\mathrm{H}_{2} \mathrm{O}\right)_{2}$

Table S1: Summary of temperature domains for $\mathrm{M}^{2+} \mathrm{M}^{3+}{ }_{2} \mathrm{~F}_{8}\left(\mathrm{H}_{2} \mathrm{O}\right)_{2}$ phases $(\mathrm{M}=\mathrm{Ni}$ and Co$)$.

\begin{tabular}{|c|c|c|c|}
\hline \multirow{2}{*}{ Phases } & \multicolumn{3}{|c|}{ Temperature domain } \\
\cline { 2 - 4 } & Crystallized phase & Amorphous phase & Oxide, formula \\
\hline $\mathrm{NiFe}_{2} \mathrm{~F}_{8}\left(\mathrm{H}_{2} \mathrm{O}\right)_{2}$ & $\mathrm{~T}<340^{\circ} \mathrm{C}$ & $340 \leq \mathrm{T} \leq 380$ & $380^{\circ} \mathrm{C}<\mathrm{T}, \mathrm{NiFe}_{2} \mathrm{O}_{4}$ \\
\hline
\end{tabular}




\begin{tabular}{|l|l|l|l|}
\hline $\mathrm{CoFe}_{2} \mathrm{~F}_{8}\left(\mathrm{H}_{2} \mathrm{O}\right)_{2}$ & $\mathrm{~T}<300^{\circ} \mathrm{C}$ & $300 \leq \mathrm{T} \leq 340$ & $340^{\circ} \mathrm{C}<\mathrm{T}, \mathrm{CoFe}_{2} \mathrm{O}_{4}$ \\
\hline
\end{tabular}
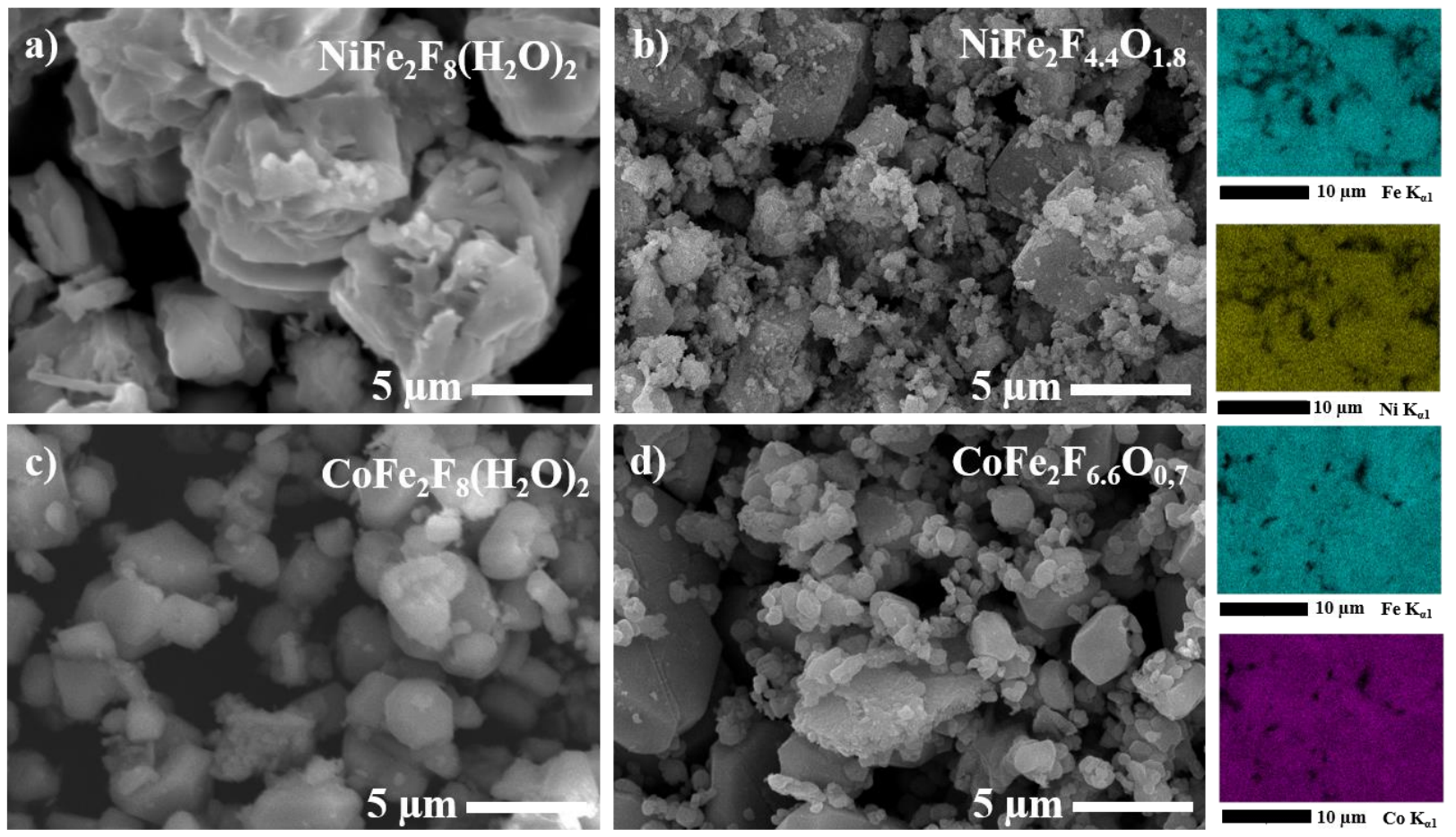

Figure S11: SEM images of a) $\mathrm{Ni}^{2+} \mathrm{Fe}^{3+}{ }_{2} \mathrm{~F}_{8}\left(\mathrm{H}_{2} \mathrm{O}\right)_{2}$ and b) $\mathrm{Co}^{2+} \mathrm{Fe}^{3+}{ }_{2} \mathrm{~F}_{8}\left(\mathrm{H}_{2} \mathrm{O}\right)_{2}$ powders before (a), c)) and after calcination (b), d)) under air. On the right: Corresponding EDS mapping on the calcined powders. 
a)

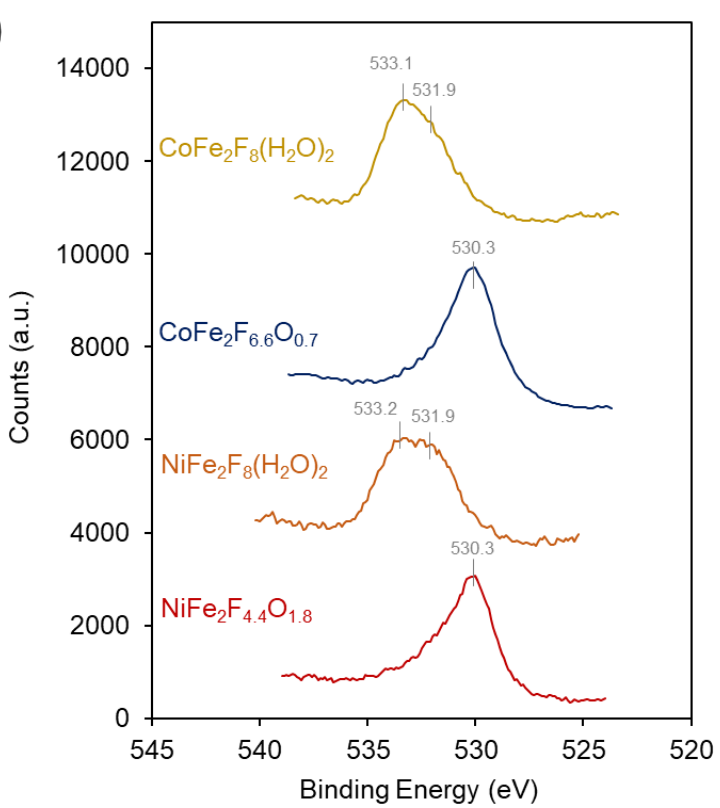

b)

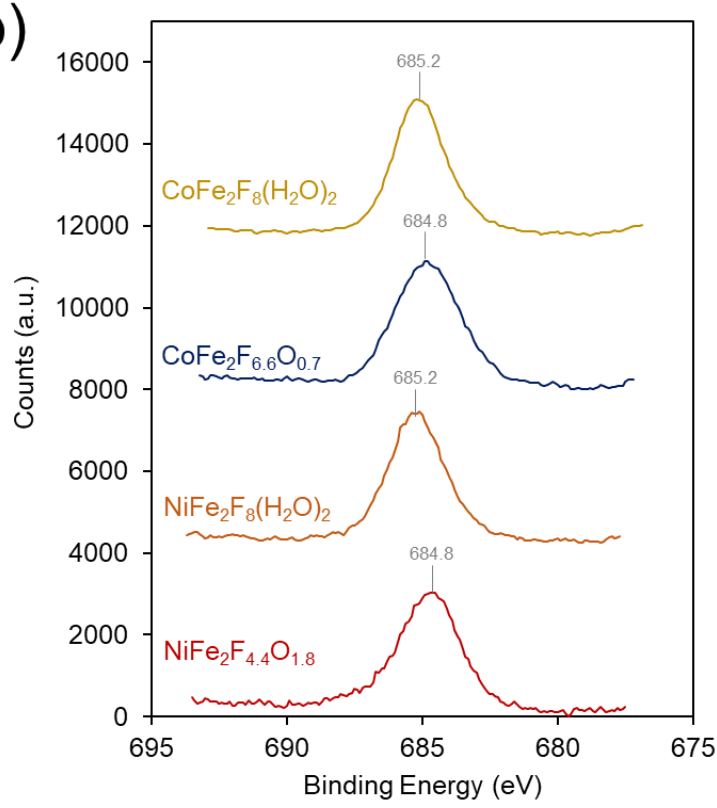

Figure S12: O1s a) and F1s b) XPS of the investigated (oxy)fluorides.

a

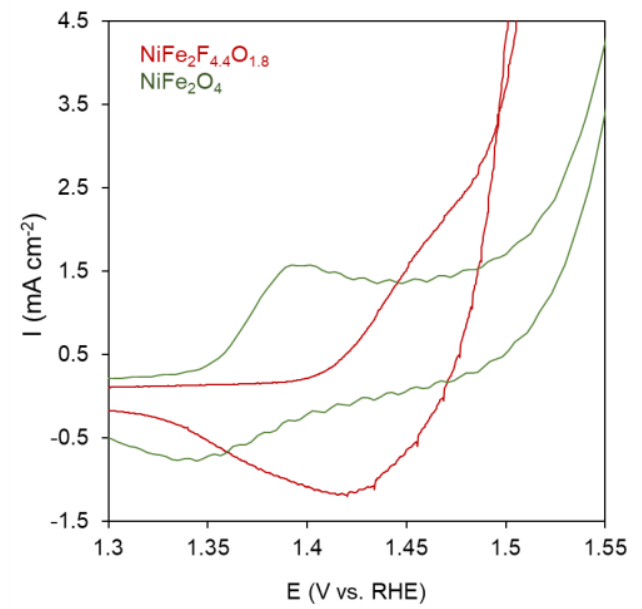

b

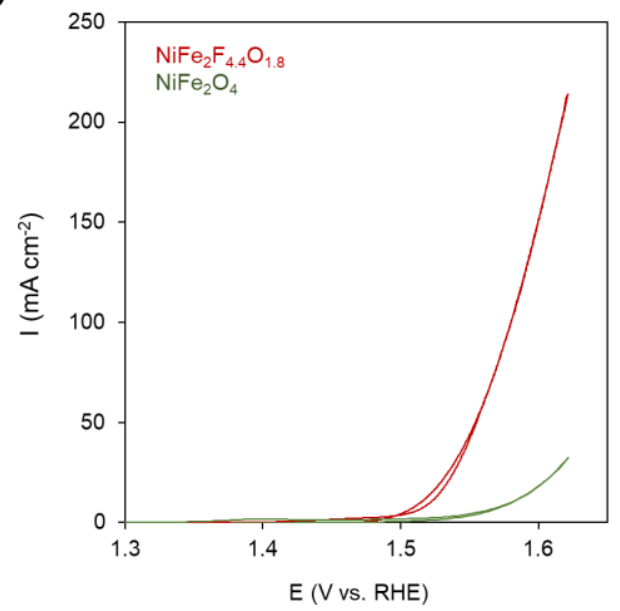

Figure S5: Cyclic volammograms of $\mathrm{NiFe}_{2} \mathrm{~F}_{4.4} \mathrm{O}_{1.8}$ and $\mathrm{NiFe}_{2} \mathrm{O}_{4}$ illustrated differences in $\mathrm{Ni}$ redox potential and water oxidation kinetics conferred by the electronegative $F$ species. (a) and (b) represent two different magnifications of the current-voltage plot. 
a)

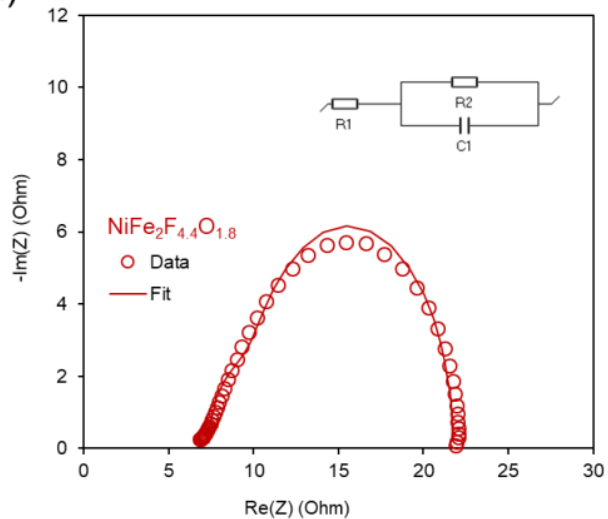

c)

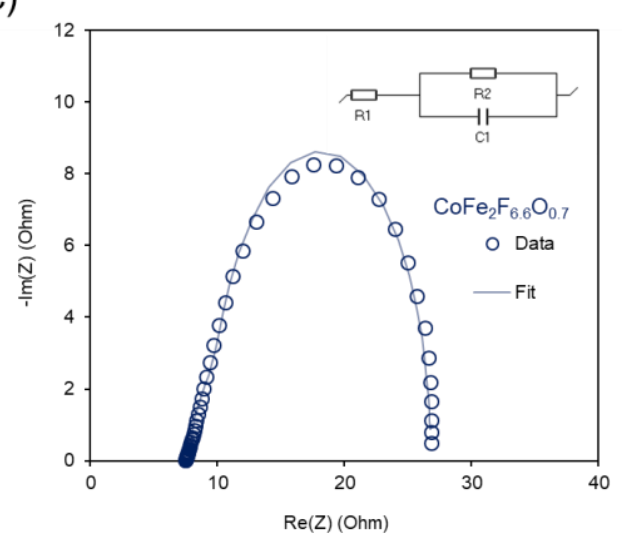

b)

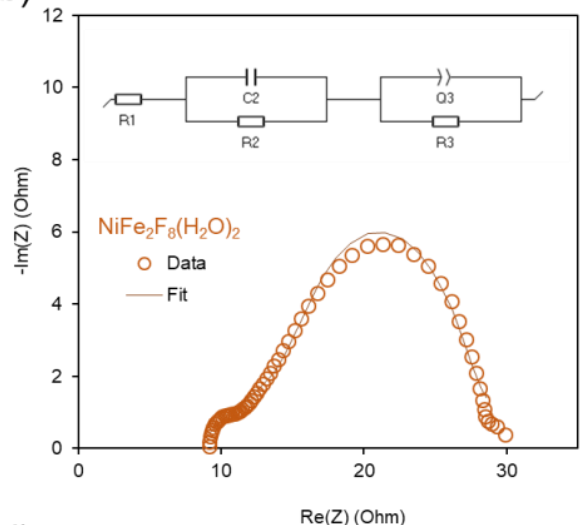

d)

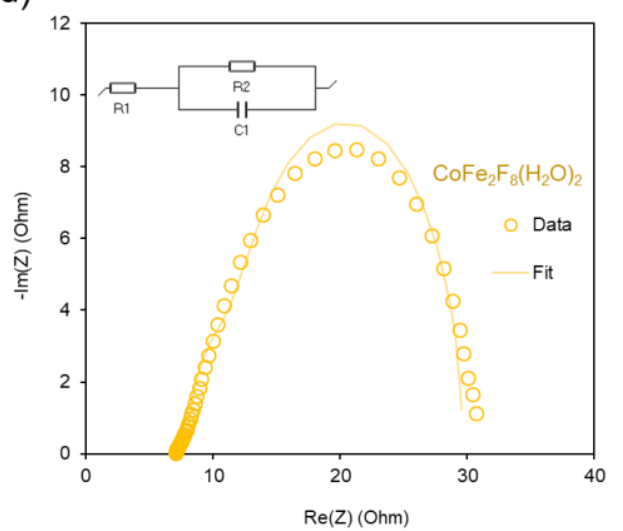

Figure S6: Example of EIS Fitting performed using a Randles circuit for (oxy)fluorides except for $\mathrm{NiFe}_{2} \mathrm{~F}_{8}\left(\mathrm{H}_{2} \mathrm{O}\right)_{2}$, which needed an extra constant phase and resistive element, indicating that charge transfer through the material was, in part, limiting the system performance. $R$ = resistive element, $C=$ capacitive element, $Q=$ constant phase element. 

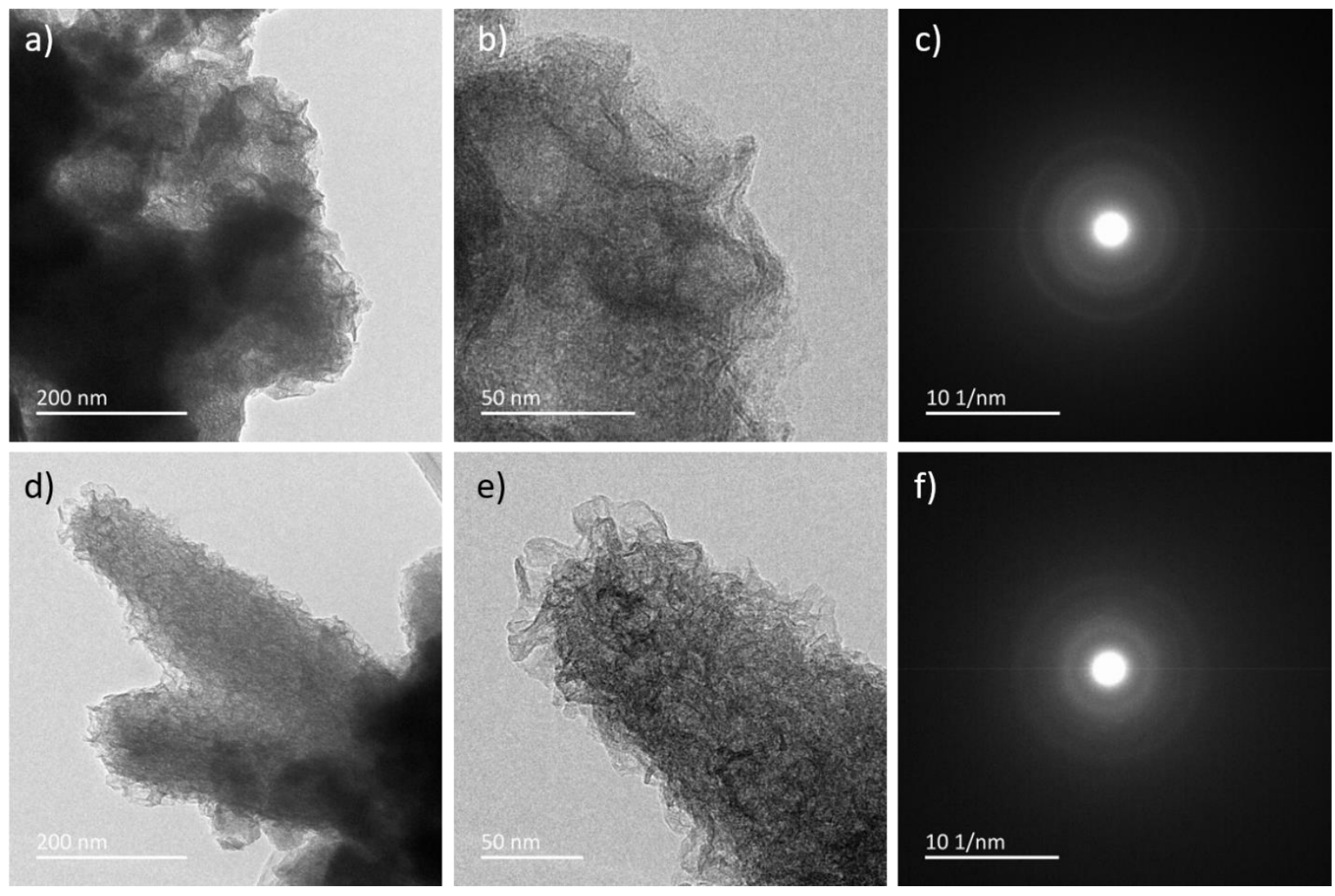

Figure S7: TEM micrographs of a), b) $\mathrm{NiFe}_{2} \mathrm{~F}_{4.4} \mathrm{O}_{1.8}$ and d), e) $\mathrm{CoFe}_{2} \mathrm{~F}_{6.6} \mathrm{O}_{0.7}$ after catalysis. c) and f) Corresponding SAED. 


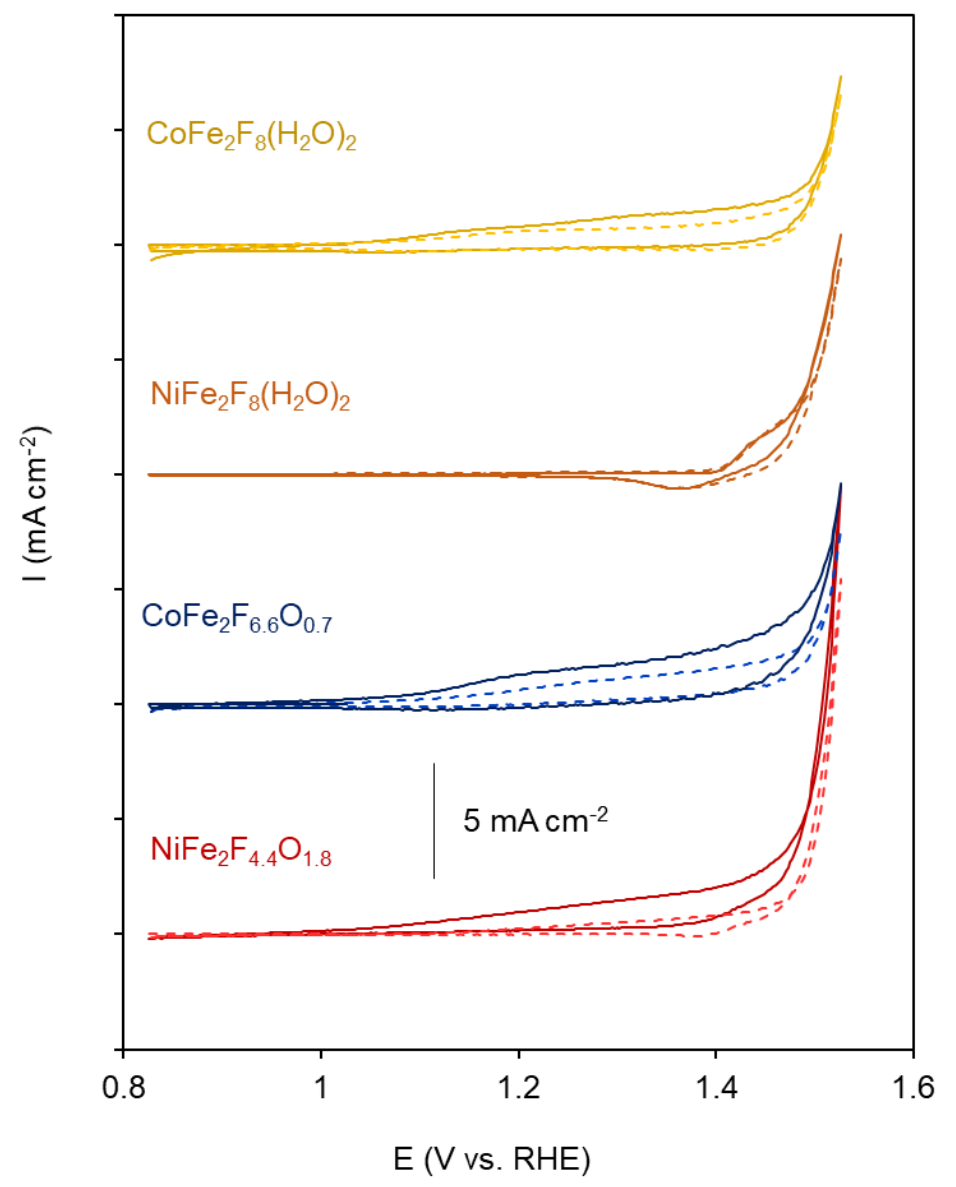

Figure S8: Cyclic voltammograms of (oxy)fluorides in 1.0 M KOH without (dotted lines) and with the addition of 10 mM methanol. 
a)

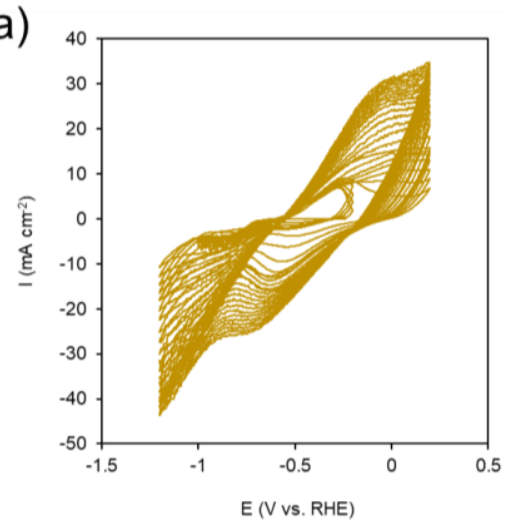

b)

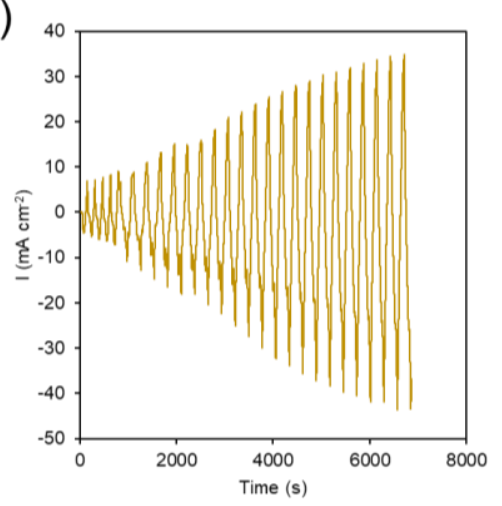

c)

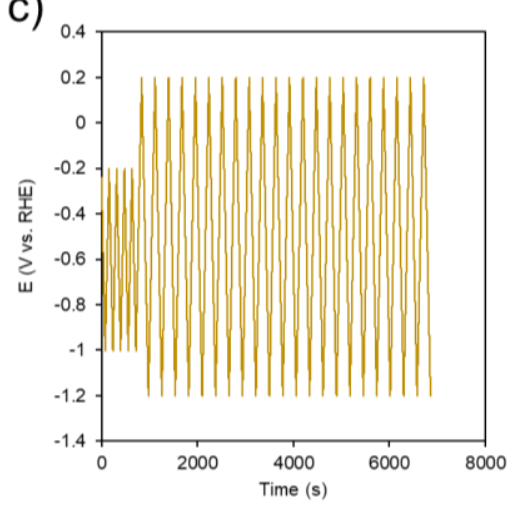

Figure S9: Electrodeposition of CoSx HER catalyst, depicted in current vs voltage a), current vs. time b) and voltage vs. time c). 